\title{
TRAINING FACE PERCEPTION IN DEVELOPMENTAL PROSOPAGNOSIA THROUGH PERCEPTUAL LEARNING
}

Sherryse L. Corrow $\mathrm{PhD}^{1,2}$

Jodie Davies-Thompson $\mathrm{PhD}^{1,3}$

Kimberley Fletcher DCLinPsy ${ }^{1,4}$

Charlotte Hills BSc ${ }^{1}$

Jeffrey C. Corrow BSc MBA ${ }^{1}$

Jason J.S. Barton MD PhD FRCPC ${ }^{1}$

${ }^{1}$ Human Vision and Eye Movement Laboratory, Departments of Medicine (Neurology), Ophthalmology and Visual Sciences, University of British Columbia, Vancouver, Canada

${ }^{2}$ Visual Cognition Laboratory, Psychology Department, Bethel University, St. Paul, MN, USA

${ }^{3}$ FaReS (Face Research, Swansea), Department of Psychology, College of Human and Health Sciences, Swansea University, UK

${ }^{4}$ Derby and Burton Hospitals NHS Foundation Trust

Address correspondence to:

Jason Barton

Neuro-ophthalmology Section K

VGH Eye Care Centre

2550 Willow Street

Vancouver, B.C. Canada

V5Z 3N9

6048754339 phone

6048754302 fax

jasonbarton@shaw.ca

Running title: Face training in developmental prosopagnosia

Key words: face recognition; vision; development; rehabilitation

Word count: abstract - , article - 


\section{ABSTRACT}

Background: Recent work has shown that perceptual learning can improve face discrimination in subjects with acquired prosopagnosia.

Objective: In this study, we administered the same program to determine if such training would improve face perception in developmental prosopagnosia.

Method: We trained ten subjects with developmental prosopagnosia for several months with a program that required shape discrimination between morphed facial images, using a staircase procedure to keep training near each subject's perceptual threshold. To promote ecological validity, training progressed from blocks of neutral faces in frontal view through increasing variations in view and expression. Five subjects did 11 weeks of a control television task before training, and the other five were re-assessed for maintenance of benefit 3 months after training.

Results: Perceptual sensitivity for faces improved after training but did not improve after the control task. Improvement generalized to untrained expressions and views of these faces, and there was some evidence of transfer to new faces. Benefits were maintained over three months. Training also led to improvements on standard neuropsychological tests of short-term familiarity, and some subjects reported positive effects in daily life.

Conclusion: We conclude that perceptual learning can lead to persistent improvements in face discrimination in developmental prosopagnosia. The strong generalization suggests that learning is occurring at the level of three-dimensional representations with some invariance for the dynamic effects of expression. 
Prosopagnosia is the inability to recognize familiar faces. It has long been described as a rare disorder following cerebral lesions (Davies-Thompson, Pancaroglu, \& Barton, 2014). More recent studies have documented a developmental form that is more common, purportedly affecting as many as 2\% of the population (Jason JS Barton \& Sherryse L Corrow, 2016; Susilo \& Duchaine, 2013). Given the importance of face recognition in social interactions, prosopagnosia can have a deleterious effect on the quality of life (Dalrymple et al., 2014; Yardley, McDermott, Pisarski, Duchaine, \& Nakayama, 2008). Hence it would be helpful to determine if this condition can be improved by rehabilitative or other medical interventions.

Our review of the literature revealed ten reports of training in acquired prosopagnosia, all single cases (Davies-Thompson et al., 2017). Approaches varied from strategic compensations, in which training is directed at improving recognition through a route that circumvents or substitutes for the damaged process, and remedial approaches, which try to restore or improve the damaged process (Bate \& Bennetts, 2014; J. M. DeGutis, Chiu, Grosso, \& Cohan, 2014). Some focused on improving memory or associative operations (De Haan, Young, \& Newcombe, 1991; Ellis \& Young, 1988; Francis, Jane Riddoch, \& Humphreys, 2002; Polster \& Rapcsak, 1996; Powell, Letson, Davidoff, Valentine, \& Greenwood, 2008; B. A. Wilson, 1987), while others targeted perceptual functions (Bate et al., 2015; Beyn \& Knyazeva, 1962; J. DeGutis, Cohan, Kahn, Aguirre, \& Nakayama, 2013; Ellis \& Young, 1988; Mayer \& Rossion, 2007; Polster \& Rapcsak, 1996; Powell et al., 2008). Overall these studies produced mixed results.

Subsequently, there have been a few studies of interventions in developmental prosopagnosia (Bate \& Bennetts, 2014; J. M. DeGutis et al., 2014). One group found that intranasal oxytocin improved face matching and short-term familiarity for faces in 10 subjects (Bate et al., 2014). A second group trained two children to pay explicit attention to facial features, with some partial benefit (Brunsdon, Coltheart, Nickels, \& Joy, 2006; Laura Schmalzl, Romina Palermo, Melissa Green, Ruth Brunsdon, \& Max Coltheart, 2008). Similarly, a third group trained a child with prosopagnosia to attend to the central features of the face, particularly the eye region, through a series of games across two phases of training with unfamiliar faces, and claimed benefit (Pizzamiglio et al., 2017). Finally, a fourth group trained subjects to perceive inter-ocular and nasal-oral distances, the 'spatial relations' that are part of the complex shape of faces, perception of which is impaired in some variants of acquired prosopagnosia (Barton, Press, Keenan, \& O'Connor, 2002). This training improved face recognition in one case (J. M. 
DeGutis, Bentin, Robertson, \& D'Esposito, 2007) and led to a larger study of 15 days of training in 24 subjects (J. DeGutis, Cohan, \& Nakayama, 2014), 13 of whom showed some benefit.

Recently we reported a study in which we used a perceptual learning approach to train face discrimination in acquired prosopagnosia, with some success (Davies-Thompson et al., 2017). While motor learning is an established rehabilitative approach in stroke patients with hemiparesis, with demonstrable effects on structural plasticity (Sampaio-Baptista, Sanders, \& Johansen-Berg, 2018), the benefit of perceptual learning for perceptual disorders has been less explored. Perceptual learning has been described as "the performance improvements in perceptual tasks as a result of practice or training" p.715 (Petrov, Dosher, \& Lu, 2005), in which experience is gained through repetitive practice of specific sensory tasks (Ahissar \& Hochstein, 2004). This experience-dependent change reflects sensory cortical plasticity, a property that persists throughout life (C. D. Gilbert \& Li, 2012). The neural level at which plasticity operates ranges from "early sensory representations to higher order changes in the way these representations are used in a task" p.715 (Petrov et al., 2005). Perceptual learning occurs for many elementary features such as orientation (Schoups, Vogels, \& Orban, 1995), motion direction (Ball \& Sekuler, 1987), depth (Fendick \& Westheimer, 1983; Ramachandran \& Braddick, 1973), and segmentation from textural cues (Charles D. Gilbert, Sigman, \& Crist, 2001; Karni \& Sagi, 1991), and processing of these features contributes to the perception of complex three-dimensional objects like faces. Most relevant for us is evidence of perceptual learning in healthy subjects for 'high-level' object representations (Baeck, Windey, \& Op de Beeck, 2012; Jiang et al., 2007), including faces (Hussain, Sekuler, \& Bennett, 2009a, 2009b), and evidence that learning improves shape-sensitive object representations (Jiang et al., 2007).

The face is a complex, dynamic three-dimensional structure. In the interests of ecological validity, we designed our perceptual learning program to train the discrimination of facial identity across variations in viewpoint and expression, over a period of about eleven weeks with thousands of trials. We created an assessment battery that could reveal whether any improvement in face discrimination had three important desirable characteristics. These included, first, generalization to new views and expressions of the trained set of faces, which would confirm that learning had occurred at the level of three-dimensional identity representations that tolerate variations in expression. Second, we determined if benefits transferred to new facial identities, which would point to the learning of a new skill rather than just over-learning a stimulus set with existing skills. Third, we evaluated if the benefits of training were maintained in the months following training. Our results in acquired prosopagnosia had shown 
that, while a control task did not alter perception, perceptual learning led to a mean improvement of $40 \%$ in perceptual sensitivity for faces, with strong generalization to new views and transfer of about half of this benefit to new facial identities (Davies-Thompson et al., 2017). Furthermore, the benefit was maintained over a 3-month period.

In the current study we asked whether a similarly encouraging result would be obtained in subjects with developmental prosopagnosia. It is not clear a priori whether this should be expected. On the one hand, subjects with developmental prosopagnosia by definition do not have visible structural lesions (J. J. Barton \& S. L. Corrow, 2016), and do show activation of the core face network by faces (G. Avidan $\&$ Behrmann, 2009). Hence one might argue that they have even more neural substrate for learning than subjects with acquired prosopagnosia. On the other hand, the fact that they have this substrate and yet did not develop good face recognition might suggest that the substrate is dysfunctional - perhaps in local microstructure (Song et al., 2015) or long-range network connectivity (G. Avidan \& Behrmann, 2009) - and may not respond to training. To address this issue, we recruited a cohort of subjects with developmental prosopagnosia, identical in number to the cohort of acquired subjects we had trained, and gave them the same perceptual learning program.

\section{METHODS}

\section{Subjects.}

We recruited ten subjects with developmental prosopagnosia. All were English-speaking, Caucasian, and lived in the Pacific Northwest region. We obtained ethical approval from the Institutional Review Board of the University of British Columbia and all subjects gave informed consent in accordance with the principles of the Declaration of Helsinki. Prior to training, subjects had five days of baseline testing. These included Goldmann perimetry and the Farnsworth-Munsell 100-hue test for colour perception, which were normal in all ten (Moroz et al., 2016). Face processing was assessed with several tests of face perception, short-term memory for faces and memory for famous faces (Table 1). Subjects were then given a neuropsychological battery that assessed general intelligence, attention, handedness, object recognition, visual-perceptual abilities, and memory (Table 2). 
Table 1. Results of neuropsychological tests.

Table 1. Neuropsychologic test results, developmental prosopagnosia.

\begin{tabular}{|c|c|c|c|c|c|c|c|c|c|c|c|c|}
\hline Test & & Max & DP008 & DP014 & DP016 & DP024 & DP033 & DP035 & DP039 & DP044 & DP201 & DP202 \\
\hline \multicolumn{13}{|l|}{ Attention } \\
\hline \multicolumn{2}{|c|}{ Trails A (seconds) } & - & 15 & 16 & 18 & 11 & 15 & 16 & 35 & 15 & 24 & 14 \\
\hline \multicolumn{2}{|c|}{ Star Cancellation } & 54 & 54 & 53 & 52 & 54 & 52 & 53 & 53 & 54 & 52 & 54 \\
\hline \multicolumn{2}{|c|}{ Visual Search } & 60 & 58 & 56 & 59 & 59 & 59 & 55 & 53 & 60 & 59 & 52 \\
\hline \multicolumn{13}{|c|}{ Memory } \\
\hline \multicolumn{2}{|c|}{ Spatial span-forward } & 16 & 8 & 10 & 10 & 10 & 9 & 11 & $5^{\#}$ & - & 9 & 8 \\
\hline \multicolumn{2}{|c|}{ Word list, immediate recall } & 48 & 34 & 39 & 29 & 43 & 42 & 39 & 31 & 39 & 36 & 31 \\
\hline \multicolumn{13}{|c|}{ Visuo-perceptual } \\
\hline \multicolumn{2}{|c|}{ Hooper Visual Organization } & 30 & 27 & 28.5 & 26 & 26.5 & 28.5 & 24 & 20 & 26.5 & 25 & 29 \\
\hline \multicolumn{2}{|c|}{ Benton Judgment of Line Orientation } & 30 & 22 & 30 & 23 & 24 & 29 & 28 & 29 & 29 & 24 & 27 \\
\hline \multirow{2}{*}{ Object: } & Object Decision & 20 & 17 & 19 & 17 & 18 & 17 & 20 & 18 & 15 & 17 & 16 \\
\hline & Progressive Silhouettes & 20 & 13 & 8 & 10 & 6 & 11 & 11 & 8 & 10 & 11 & 8 \\
\hline \multirow{4}{*}{ Spatial: } & Dot Counting & 10 & 10 & 10 & 10 & 10 & 10 & 9 & 8 & 10 & 10 & 10 \\
\hline & Position Discrimination & 20 & 18 & 20 & 20 & 20 & 20 & 19 & 20 & 20 & 20 & 20 \\
\hline & Number Location & 10 & 9 & 10 & 10 & 10 & 9 & 10 & 10 & 10 & 10 & 10 \\
\hline & Cube Analysis & 10 & & & & & & & & & & \\
\hline \multicolumn{13}{|l|}{ Imagery } \\
\hline \multicolumn{2}{|c|}{ Mental Rotation } & 10 & 7 & 10 & 10 & 10 & 10 & 10 & 10 & 10 & 5 & 9 \\
\hline
\end{tabular}

bold denotes impaired, - denotes test not administered

Diagnostic criteria for developmental prosopagnosia have been discussed recently (J. J. Barton \& S.

L. Corrow, 2016; Dalrymple \& Palermo, 2016). Following the proposed guidelines, our inclusion criteria were, first, an in-person clinical interview that documented a subjective report of life-long difficulty in face recognition, corroborated by a high score on a questionnaire, the 20 -item Prosopagnosia Index (Shah, Gaule, Sowden, Bird, \& Cook, 2015). Second, we required objective confirmation of impaired face recognition on tests, including at least two of (i) a discordance between preserved word memory and impaired face memory on the Warrington Recognition Memory Test for Faces and Words that was in the bottom 5th percentile (Warrington, 1984), (ii) a score at least two standard deviations below the control mean on the Cambridge Face Memory Task (B. C. Duchaine \& Nakayama, 2006), (iii) a score at least two standard deviations below the control mean on an Old/New 
faces test (B Duchaine \& Nakayama, 2005) and (iv) a score at least two standard deviations below the control mean on a Famous Faces Test.

Table 2. Subject demographics and face-related scores.

\begin{tabular}{|c|c|c|c|c|c|c|c|c|c|c|}
\hline subject & age & gender & Old/New Test & P120 & CFMT & & WRI & & famous & CFPT \\
\hline & (yrs) & & (faces) & & & face $/ 5$ & vord/ & re & faces $(/ 6$ & \\
\hline $\begin{array}{l}\text { normative limit } \\
\text { developmental }\end{array}$ & rosopa & agnosia & 2.09 & 60.5 & 42.1 & * & * & 10 & 45.3 & 61.6 \\
\hline DP008 & 61 & female & 1.46 & 72 & 36 & 36 & 49 & 13 & 43 & 48 \\
\hline DP014 & 42 & male & 0.67 & 91 & 32 & 30 & 48 & 18 & 8 & 64 \\
\hline DP016 & 52 & female & 2.06 & 87 & 41 & 37 & 49 & 12 & 37 & 48 \\
\hline DP024 & 35 & female & 1.89 & 75 & 41 & 38 & 50 & 12 & 14 & 62 \\
\hline DP033 & 49 & female & 2.06 & 84 & 29 & 39 & 50 & 11 & 32 & 52 \\
\hline DP035 & 40 & male & 1.46 & 84 & 36 & 35 & 49 & 14 & 9 & 86 \\
\hline DP039 & 50 & male & 1.81 & 85 & 22 & 46 & 50 & 4 & 37 & 54 \\
\hline DP044 & 36 & female & 2.34 & 95 & 40 & 34 & 49 & 15 & 26 & 68 \\
\hline DP201 & 53 & female & 3.24 & 94 & 42 & 44 & 50 & 6 & 41 & 32 \\
\hline DP202 & 20 & female & -0.21 & 86 & 33 & 32 & 50 & 18 & $(-)$ & 64 \\
\hline
\end{tabular}

CFMT $=$ Cambridge Face Memory Test, CFPT $=$ Cambridge Face Perception Test

WRMT $=$ Warrington Recognition Memory Test

* criterion varied with age

$(-)$ not done

We excluded subjects with a history of significant psychiatric disorders or degenerative disorders of the central nervous system. Four subjects reported mild concussions many years prior, with no residual effects. We required visual acuity of 20/60 or better in at least one eye, and no evidence of bilateral impairments of the central visual field on perimetry. One subject had had a unilateral retinal detachment that had been corrected surgically but now had normal visual acuity and fields in both eyes. We excluded subjects with results indicating a general visual agnosia or general amnesia on the neuropsychological battery (Table 2). To exclude autism spectrum disorders, all subjects had a score less than 32 on the Autism Questionnaire (Baron-Cohen, Wheelwright, Skinner, Martin, \& Clubley, 2001).

As an additional step, to exclude early-onset acquired structural lesions causing prosopagnosia, we performed MRI scans with a 3.0 Tesla Phillips scanner in seven subjects (MRI was contraindicated in three subjects, DP033, DP039 and DP202). This included a whole brain T1-weighted echoplanar 
imaging sequence and a whole brain coronal fluid-attenuated inversion recovery sequence. All scans were normal as determined by a neurologist (JB).

\section{Timeline}

The timeline for the study is presented in Figure 1. All subjects visited the laboratory on three occasions for behavioral and neuroimaging evaluations. On their first visit, subjects were introduced to the on-line training platform that also hosted the six on-line assessments. They did the first of these six on-line assessments during this visit and then the remaining five at home over one week, with no more than one per day. After completing this initial characterization, subjects were pseudo-randomly assigned to begin with either training (train-first group) or the control television task (train-second group). Both training and the control television task took approximately 11 weeks. Following completion of this first period, subjects completed the second assessment. They did the same six on-line assessments at home, then returned to the laboratory the following week for the second set of behavioral and neuroimaging assessments.

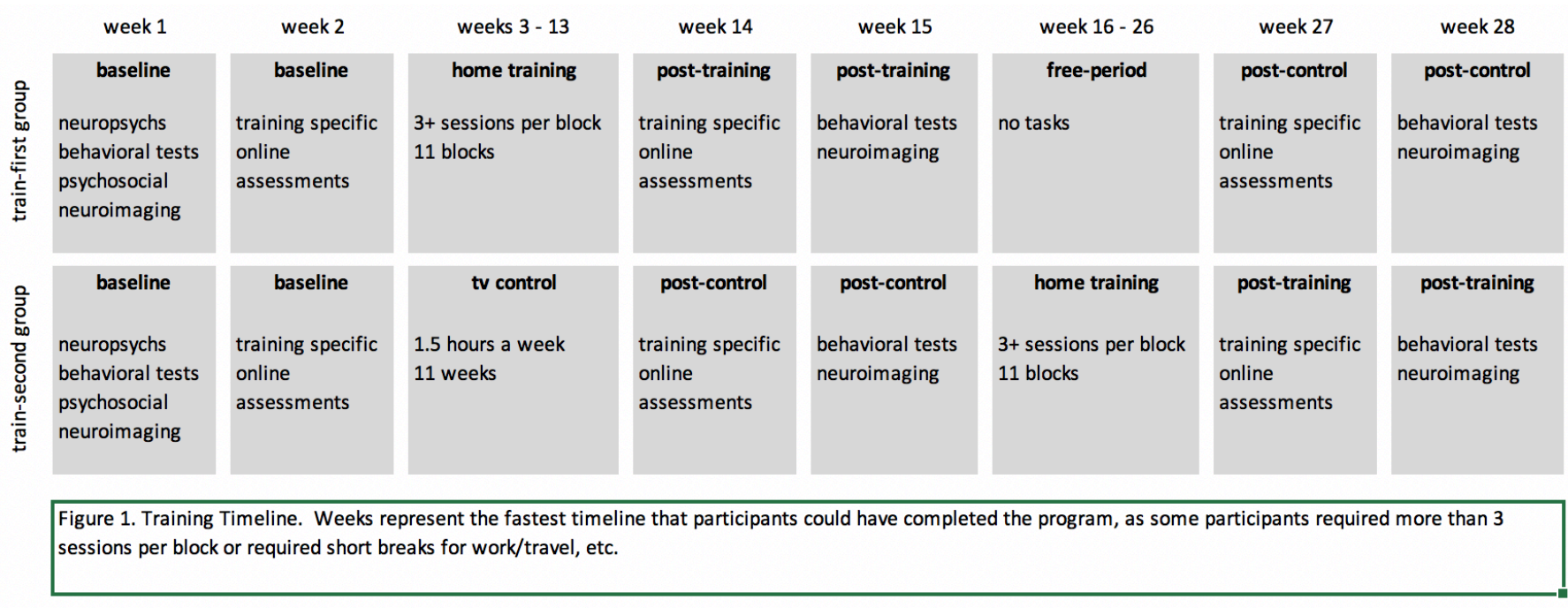

Subjects then went home and those who had done the control television task now did the training in this second period. In a change from our study of acquired prosopagnosia, the subjects who had done the training first simply returned to their normal daily activities, a 'free period', instead of doing the control television task. In the acquired prosopagnosia study we had found that, in the subjects who had done training first, the benefits of training were still evident 3 months later, after the period when they were engaged in the control television task. One could ask whether the attention to faces required 
during the control task might have played a role in maintaining benefit. By eliminating the control task in those subjects who did training first, we aimed to determine if the benefit of training would be maintained even if subjects just resumed their daily routines.

Finally, at the end of this second period, subjects performed the six on-line assessments in the week prior to returning to the laboratory to complete the third and final set of behavioral and neuroimaging assessments.

\section{Face Training protocol}

We designed the Face Training program (www.hvelab.org/facetraining) to be an on-line resource that allows users to train on their own computers at home. Experimenters can assign any given number of sessions to a subject, with a new training session available on completion of the previous session. The experimenter can monitor each subject's progress, as results from a session are available to the experimenter immediately after its completion. All training and on-line assessments are performed on this system with each subject having their own account.

Stimuli. We photographed 12 Caucasian males without facial hair in a local photography studio. Lighting was held constant across all photographs and models. Models were photographed at five angles of lateral rotation $(0=$ frontal view, 10, 20,30,40 $)$ and five expressions (neutral, happy, sad, angry, surprise), resulting in 25 images of each of the 12 males. External features (ears and hair) and distinguishing textural features (moles, etc.) were removed with Adobe Photoshop CS5.1 (www.adobe.com). Images were converted to grey-scale and luminance-matched. Faces were unknown to all subjects.

Next we created images where the emotional expression varied in degree by morphing between each of the four expressions and the neutral face of the same person. Morphing was done with Abrosoft FantaMorph 5 (www.fantamorph.com), with approximately 100 fiducial points marking the features and outline of each of the two images, resulting in gradual transition from one facial image to another. From the series of morphed images we selected faces with 10\% (i.e. 10\% expressive and 90\% neutral), $33 \%, 66 \%$ and $100 \%$ expressive content for each emotional expression. This was repeated for each of the five viewing angles, resulting in a total of 85 faces for each of the 12 identities. 
We then separated the 12 face identities into two sets of three pairs. Each subject trained on one set of three pairs and the other set was used for testing as untrained faces. Five subjects were pseudorandomly assigned to train on Set A, and the other five on Set B. Face pairs and face sets were equated approximately in discriminability in pilot work described previously (Davies-Thompson et al., 2017).

Within a pair of two identities, corresponding images (e.g. the $10 \%$ angry faces in $0^{\circ}$ view) were morphed between the first and the second person in increments of $2.5 \%$, creating a gradual transition of one identity to another. For a single image pair, this resulted in 40 morphed images. This process was repeated for each of the 85 base images for each of the six pairs of identities.
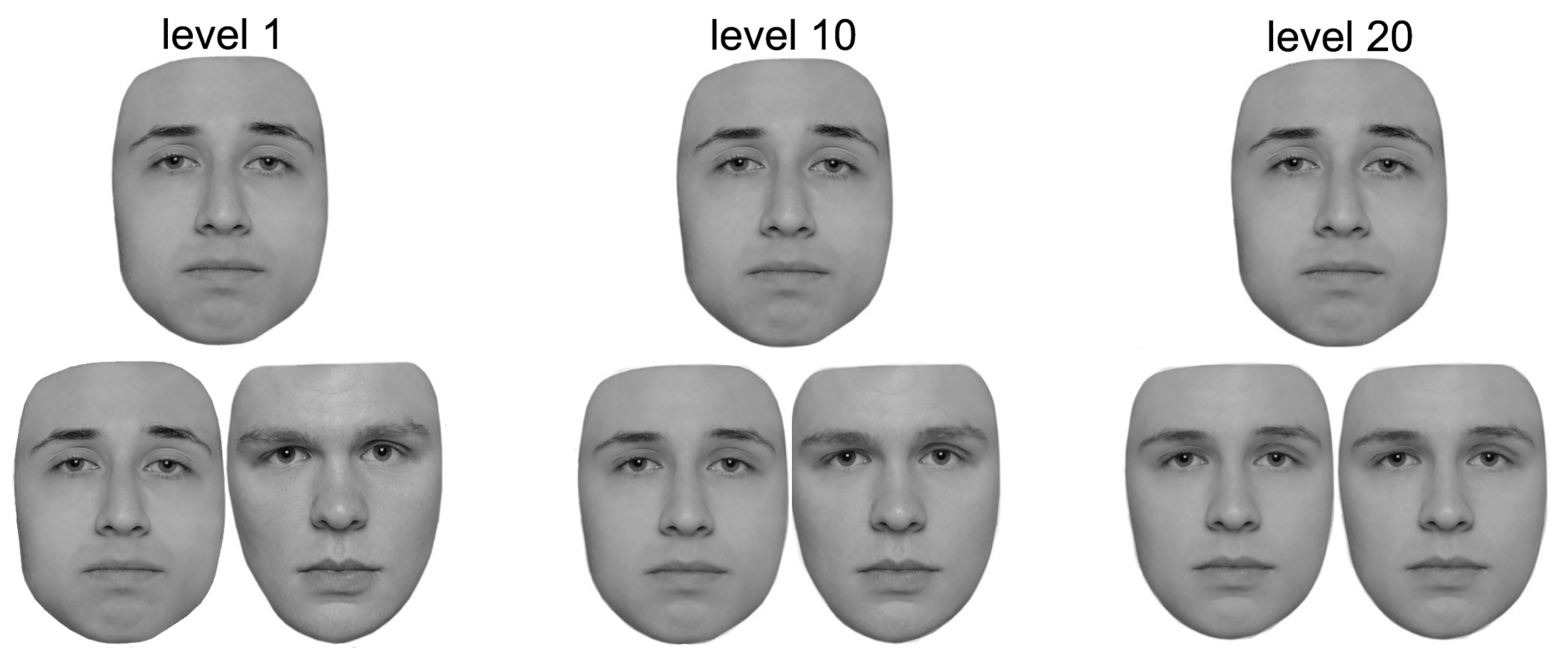

Figure 2. Example of training trials from block 1. In a trial subjects saw three faces and indicated which of the bottom two choice faces most resembled the top target face. The difficulty of the trial was manipulated by choosing the choice faces from a morph spectrum between the target face and a second paired face. When the two choice faces are the original faces-essentially the extreme ends of the morph spectrium - this is the easiest discrimination level, level 1. Level 10 takes as two choice faces the morphed images with face A;face B ratios of [22.5\%:77.5\%] and [77.5\%:22.5\%] to creates a trial of medium difficulty. Pairing images near the center of the morph series creates the most difficult trial, level 20, with choice faces that have face A:face B ratios of [47.5\%:52.5\%] and [52.5\%:47.5\%]. A session begins with a level 1 trial and a staircase procedure increases the difficulty level by one if they give a correct answer, and decreases it by six after an error. 
Within-session training protocol. Each training trial presented three faces (Figure 2). The top face was always one of the original unmorphed images of a pair, in $0^{\circ}$ view with a neutral expression. Below were two choice faces, and the task was to indicate with a keyboard press which of these two faces most resembled the top face. This method aimed at training perceptual processes and shared design elements with the Philadephia Face Similarity Test (Thomas, Lawler, Olson, \& Aguirre, 2008) and another study of perceptual face training (Bate et al., 2015). The design reflected evidence from previous studies of perceptual learning of faces that suggest an advantage for simultaneous over sequential presentation of faces in discrimination tasks (Mundy, Honey, Downing, et al., 2009; Mundy, Honey, \& Dwyer, 2007, 2009) and better perceptual learning for faces shown alongside similar rather than dissimilar faces (Dwyer \& Vladeanu, 2009).

To reduce the use by subjects of a serial feature-by-feature analysis instead of evaluating the whole face, the top face disappeared after two seconds while the two choice faces remained until a response was made. To minimize low-level image matching, the size of the bottom two images varied randomly between trials, being $100 \%, 85 \%$, or $70 \%$ of the size of the top face. Such size variation may also enhance the benefits of training object recognition (Furmanski \& Engel, 2000). To maintain the motivation of subjects we provided trial-by-trial feedback, with a green tick appearing briefly on the screen after a correct response and nothing after an incorrect one.

The level of difficulty of a trial was determined by which pair of images from the morphed series were shown as the two choice faces (Figure 2). At the easiest level, level 1, these were the two unmorphed images from the opposite ends of the morph spectrum. At the hardest level, level 20, these were the two morphed images on either side of the center of the morph spectrum (47.5\% of one identity and $52.5 \%$ of the other). Note that, apart from level 1 , none of the choice faces were identical to the target face. All sessions began with the easiest level. A staircase design controlled the difficulty levels of subsequent trials. This followed the rules of an up-down weighting procedure (Kaernbach, 1991). To keep the subjects training near an $85.7 \%$ correct perceptual threshold, we used a 1-down/6-up staircase: that is, a correct response resulted in the next trial increasing in difficulty by one level, while an error led to a decrease in difficulty by six levels. During training, the trials for the three identity pairs were presented in interleaved, independent staircases.

After subjects had made either 12 reversals, 6 up and 6 down (Wetherill \& Levitt, 1965), or correctly answered the highest difficulty level 6 times, they were then given another 200 training trials, with the staircase continuing to vary in difficulty. This was done in parallel for each of the three pairs. 
Thus subjects performed 600 more trials after reaching threshold, with the entire session taking approximately 30 to 40 minutes. This amount of training is in the range of the duration or number of trials used by previous studies that obtained perceptual learning for faces, hyperacuity and texture discrimination (J. M. DeGutis et al., 2007; Fahle \& Morgan, 1996; Karni \& Sagi, 1991). At the end of a session subjects were shown their average performance for that session, as a summarized form of feedback.

Between-session training protocol. Each subject completed three sessions each week on any days they preferred. As sleep may consolidate perceptual learning (Fenn, Nusbaum, \& Margoliash, 2003; Gais, Plihal, Wagner, \& Born, 2000; Karni, Tanne, Rubenstein, Askenasy, \& Sagi, 1994), we asked subjects to complete sessions in the early evenings and to do only one session per day. Subjects performed at least three sessions for each training block, and continued repeating sessions for a given block until there was no further improvement. Improvement was defined as a 5\% or greater increase in performance threshold between two sequential sessions with less than a $5 \%$ increase in reaction times, so that this was not due to a speed-accuracy trade-off.

After meeting these criteria for completing a block, subjects advanced to the next of a series of eleven blocks (Figure 3). The first of these eleven blocks presented the two choice faces with the same $0^{\circ}$ view and neutral expression as the top face. While the top face was always shown in $0^{\circ}$ view and with a neutral expression, subsequent blocks gradually introduced greater variations in view (blocks 2 to 4), expression (blocks 5 to 8) or in view for $100 \%$ expression (blocks 9 to 11) in the choice faces. Expressions included happy, sad, and angry faces in 10\%, 33\%, 66\% and 100\% morphing increments, while views included $10^{\circ}, 20^{\circ}$ and $40^{\circ}$ rotations from the frontal position. (The $30^{\circ}$ view and 'surprised' expressions were not used in training but reserved for testing as untrained stimuli.) Thus when subjects reached the more difficult training blocks, they were making perceptual discriminations across substantial variations in view and expression, an important requirement in daily life. Adding these variations in dimensions irrelevant to identity may also promote one hypothesized aspect of perceptual learning: learning to attend to detectors tuned to the most informative stimulus dimensions (Palmeri, Wong, \& Gauthier, 2004). Also, the gradual progression from easy to difficult tasks may be an important feature of effective protocols for perceptual learning (Ahissar \& Hochstein, 2004). 


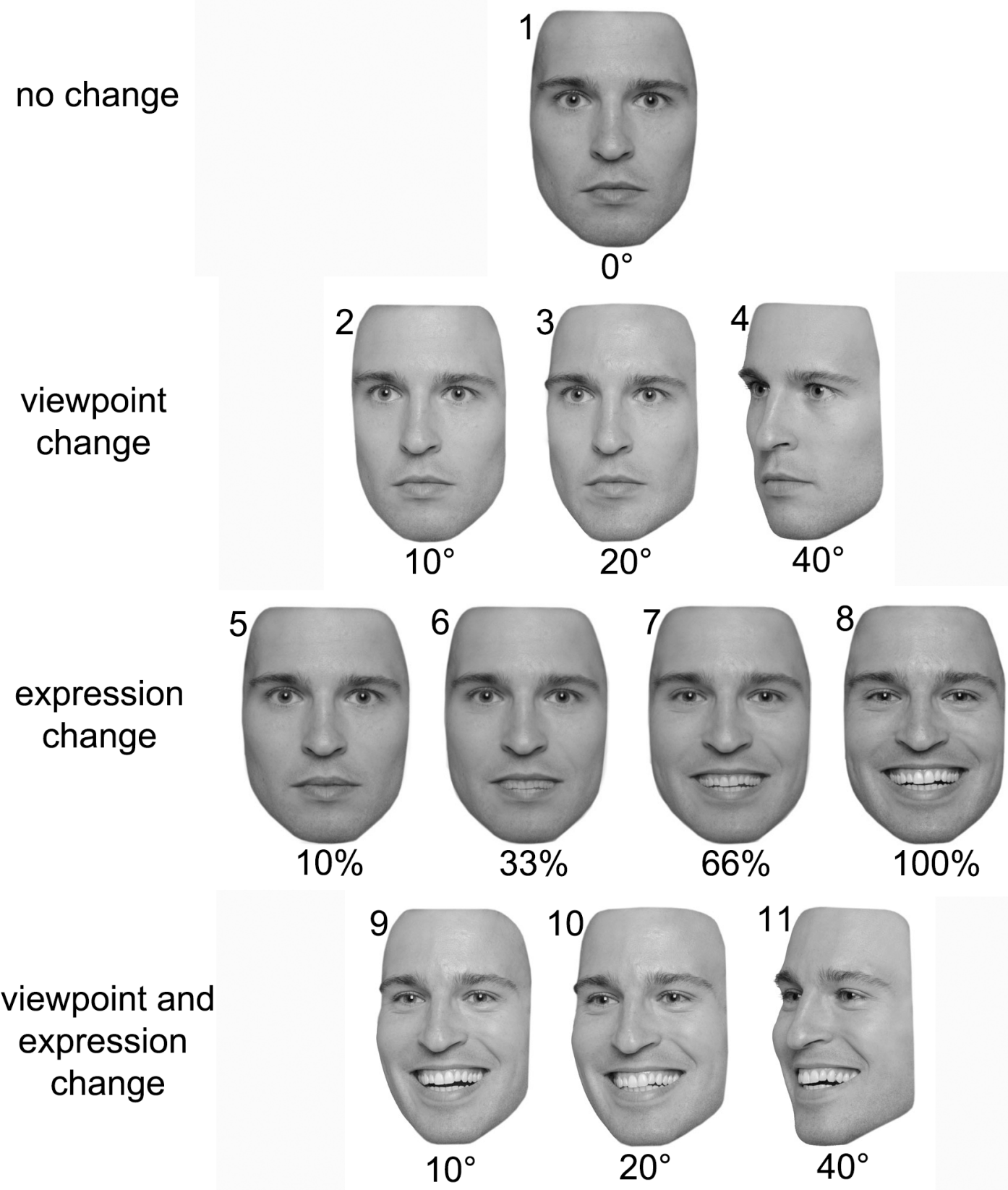

Figure 3. Example of choice faces from the 11 different training blocks. Block number (1 to 11) is indicated in the top left corner of each facial image. The target face is always seen in frontal view with a neutral expression, but the choice faces vary. In block 1, choice faces also have a frontal view and neutral expressions. In blocks 2 to 4 , the difference in viewpoint increases from $10^{\circ}$ to $40^{\circ}$ of rotation. In blocks 5 to 8 the expression difference increases in terms of morphing between neutral and expressive faces, from [90\% neutral:10\% expression] to [0\% neutral:100\% expression]. In blocks 9 to 
11 the viewpoint difference increases for the 100\% expression face. Shown here are examples from one emotional expression (happy), among the three used in training (happy, sad, angry).

\section{Control task}

To determine if any benefits were due to the training program specifically or simply to enforced attention and exposure to faces, we randomized five subjects in the training-second group to start with a control task. Subjects watched episodes from a British television series of their choice (Midsomer Murders, Doc Martin, Taggart, Prime Suspect, Foyle's War, or Cracker), as long as they were unfamiliar with either the faces of the actors or the names of the characters. Subjects and a close relative confirmed their lack of prior knowledge about them. Anecdotally, participants with prosopagnosia often report a lack of interest in television shows due to the difficulty of following the plot. Therefore, the purpose of the TV control was to increase participants' exposure to faces without explicitly providing training of face processing ability. The duration of the control task approximated that of the training, with each subject undergoing approximately 1.5 hours of watching episodes per week for 11 weeks. Their other television viewing was not regulated. To ensure subjects were paying attention to the television programs, each week we asked them 6 questions about the plots and events in the previous week's episodes. All subjects were able to answer at least 4 questions correctly for each episode, with over $90 \%$ of questions answered correctly.

\section{Evaluation of training effects}

Primary outcomes. These assessments used the same staircase procedure as training: the average level of the 12 reversals was their 'perceptual sensitivity' to morphed changes, which we expressed as a percentage of the morph range (one level equals 5\%). Assessment differed from training procedures in that a) no feedback was given, b) all three faces remained on the screen until a decision was made, c) staircases were not followed by the added 600 training trials, and c) assessments included face identities from both set $\mathrm{A}$ and set $\mathrm{B}$, only one of which had been used during training.

There were six tests combining the two sets (Figure 4). The first two tests assessed perception using the views and expressions seen during training. Test 1 showed the easiest training level $\left(0^{\circ}\right.$ view, neutral expression), while test 2 showed the most difficult level ( $40^{\circ}$ view, $100 \%$ expression change). 
The next two tests assessed perception for an untrained view, namely $30^{\circ}$. Test 3 presented this untrained view with the neutral expression and test 4 with $100 \%$ of trained expressions. The final two tests used the untrained expression of surprise. Test 5 showed this in $0^{\circ}$ view while test 6 presented the untrained surprised expression in the untrained view of $30^{\circ}$. Subjects completed all six test sessions within two weeks, with a maximum of two sessions on any given day, separated by at least 1 hour. Tests were done in the same order at each assessment. Within each test, half the faces were from the trained face-set and half from the untrained face-set, whose results were later separated to give 12 test scores ( 1 to 6 for trained faces, 7 to 12 for untrained faces).

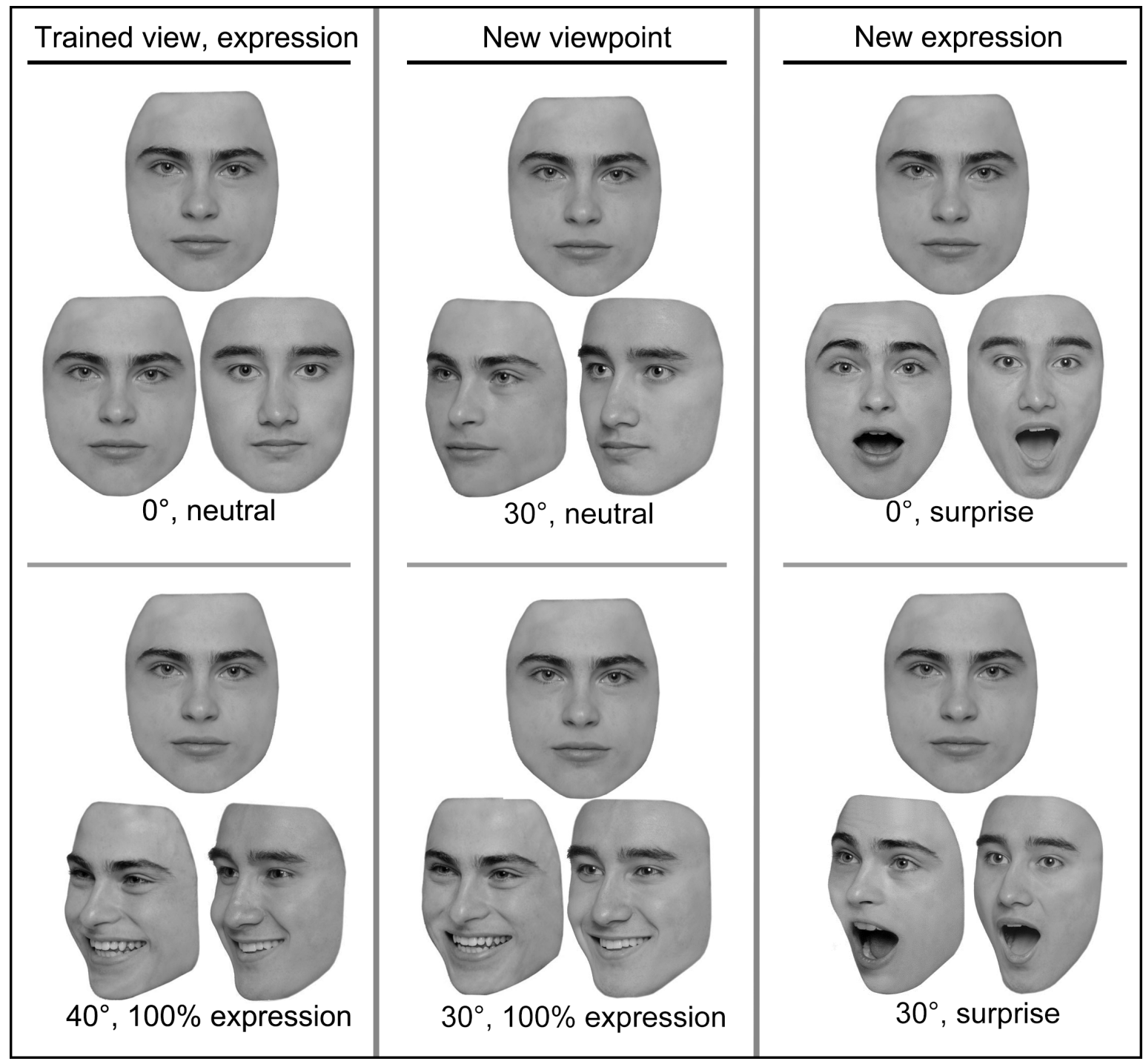

Figure 4. Example trials of the six on-line assessments. Tests 1 and 2 (left column) used views and expressions seen in training (old-image). Tests 3 and 4 (middle column) used the new, untrained viewpoint of $30^{\circ}$. Tests 5 and 6 (right column) used the new, untrained expression of surprise (test 6 
also used the untrained viewpoint of $30^{\circ}$ ). One set of six assessments (tests 1 to 6 ) used the set of facial identities on which the subject trained, while the second set (tests 7 to 12) used the set of facial identities not used in training.

Secondary outcomes. On each of their three visits to the laboratory subjects performed the Cambridge Face Memory Test, which assesses short-term familiarity for faces (B. C. Duchaine \& Nakayama, 2006) and the Cambridge Face Perception Test, which tests perceptual discrimination of faces (Bradley Duchaine, Germine, \& Nakayama, 2007). To eliminate learning effects and to stabilize their score, each subject completed the Cambridge Face Perception Test five times at each visit, with a maximum of three per day, and the average of the best two taken as their score. Subjects also performed the Warrington Recognition Memory test (Warrington, 1984). To guard against experimenter bias, the person administering these tests was blinded to whether the subject had just done training or the control task.

Impressions of the subjects. As with our prior study and other recent training studies (Bate et al., 2015; J. DeGutis et al., 2014; Mayer \& Rossion, 2007), we asked subjects to describe the effects of training on their experience with faces in daily life, after variable periods of several months.

\section{ANALYSIS}

\section{Scoring of Primary Outcomes}

To represent the effect of an intervention (either training or the non-training periods) we calculated an 'intervention effect' by subtracting the perceptual sensitivity before the intervention from that after the intervention. Thus, if the subject performed the non-training period first and the training period second (train-second group), non-training effects were evaluated by subtracting the first (baseline) and second assessments, while the training effect was evaluated by comparing the second and third assessments. Thus, for this analysis, the TV control condition and free period were collapsed. For each research question, we also conducted a first-phase analysis that did not collapse across different types of the non-training period.

For the on-line assessments, we compared three change indices. The 'old-image' index was for trained stimuli, combining the results of Tests 1 and 2. The 'new-view' index was for the untrained 
viewpoint of $30^{\circ}$, combining the results of Tests 3 and 4 . The 'new-expression' index was for the untrained expression of surprise, combining the results of Tests 5 and 6 . This was done for the set of faces used in training and the new untrained set of faces separately.

\section{Primary Outcomes Analysis}

We first asked if there was a general improvement in perceptual sensitivity during the training period relative to the non-training period. Therefore, we conducted a 2 (intervention: training vs nontraining) x 2 (face set: trained vs untrained) x 3 (testing condition: old-image, new-view, newexpression) repeated measures ANOVA. Due to small sample size, we collapsed the TV control and the free period control into a single non-training period. Therefore, we call this the 'general ANOVA.' Then, to control for potential differences in face recognition ability at the start of the study, we conducted the same analysis but included the average performance on the baseline assessments as a covariate (ANCOVA). Finally, to better evaluate the effect of the training program relative to the TV control task, we conducted a 2 (intervention: training vs TV control) x 2 (face set) x 3 (testing condition: old-image, new-view, new-expression) mixed ANOVA with intervention as a betweensubjects factor and face set and testing condition as within-subjects factors. Therefore, we call this the 'first-phase ANOVA' as it examined only the first phase of the study comparing the frain-first group with the train-second group. For each of these analyses, we specifically examined the main effect of intervention to evaluate the overall effect of the training program. Finally, at an individual level, we computed for each subject an average change, averaged across all 12 tests and determined with t-tests if the mean change for any individual subject was significantly different from zero.

We then asked whether learning would generalize to new viewpoints and expressions. For this analysis, we are primarily interested in the intervention $\mathrm{x}$ testing condition interaction, but only for trained faces. Therefore, we conducted a 'general' 2 (intervention: training vs non-training) x 3 (testing condition: old-image, new-view, new-expression) repeated measures ANOVA for only the trained faces. We repeated this analysis adding baseline performance as a covariate (ANCOVA). In addition, we conducted a 'first-phase only' 2 (intervention: training vs TV control) x 3 (testing condition: oldimage, new-view, new-expression) mixed ANOVA with intervention as a between-subjects factor and testing condition as a within-subjects factor. For each of these analyses, we specifically examined the interaction between intervention and testing condition. Finally, we conducted a priori comparisons 
using paired-sample t-tests to evaluate the difference between the training and non-training periods for the new-view and new-expression conditions separately,

Third, we were interested in whether the effects of training would generalize to new identities. If so, this would be seen as an intervention by face-set interaction. Therefore, using the same analyses that were conducted to examine a training effect (above), we examined the intervention by face-set interaction for the general ANOVA, ANCOVA, and first-phase ANOVA.

Finally, to assess maintenance of benefit in the five subjects who did training first, we performed a paired t-test between the mean perceptual sensitivity immediately after training with that after the 3 months of the free period.

All analyses were a priori unless otherwise indicated. Due to rather small sample sizes, we conducted linear contrasts to follow up on any significant main effect or interaction. Unless otherwise indicated, there were no violations of the assumptions for parametric statistics for each of the tests conducted.

Secondary outcomes. For secondary endpoints, we examined the impact of training on the other tests of face perception. To simplify matters we assessed the absolute change during the training period and, using paired one-sample t-test, determined if any changes were significantly different from zero. Similarly, we assessed the absolute change during the control period for the 5 subjects who completed the TV control.

Impact of subject variables. Subject variables may impact the efficacy of training (Bate \& Bennetts, 2014). First, we examined if prosopagnosia severity had an impact by looking for correlations between the absolute change in mean perceptual sensitivity after training and baseline performance on each of the secondary tests of face perception, as well as baseline perceptual sensitivity. Second, given speculation that better results may occur in younger adults (Bate \& Bennetts, 2014), we tested for a correlation of training benefit with subject age.

\section{RESULTS}

\section{a. Primary outcomes.}




\section{Overall, did the training produce an improvement (Table 3)?}

The general ANOVA showed a significant main effect of intervention $\left(\mathrm{F}_{(1,9)}=7.485, \mathrm{p}<0.023\right)$

with a large effect size $\left(\eta^{2}=.454\right)$, suggesting that there was greater improvement during the training period $(\mathrm{M}=13.35$, S.E. $=3.27)$ than during the non-training period $(\mathrm{M}=1.992$, S.E. $=1.61$; Figure 5). However, this was qualified by a significant intervention $\mathrm{x}$ face set interaction (see below under generalization).

Table 3. Average perceptual sensitivity scores at baseline, immediately after training, and immediately after the non-training period. Results are presented separately for those who completed the training first (followed by the free-period) and those who completed training second (after completing the TV control).

Table 3. Primary outcomes in mean perceptual sensitivity

Baseline Training Non-

Train First 61.42 (8.73) 75.07 (4.32) 76.52 (2.9)

$\begin{array}{llrl}\text { Train } & 45.47 & 61.05(12.0) & 48.01 \\ \text { Second } & (10.57 & (15.47)\end{array}$



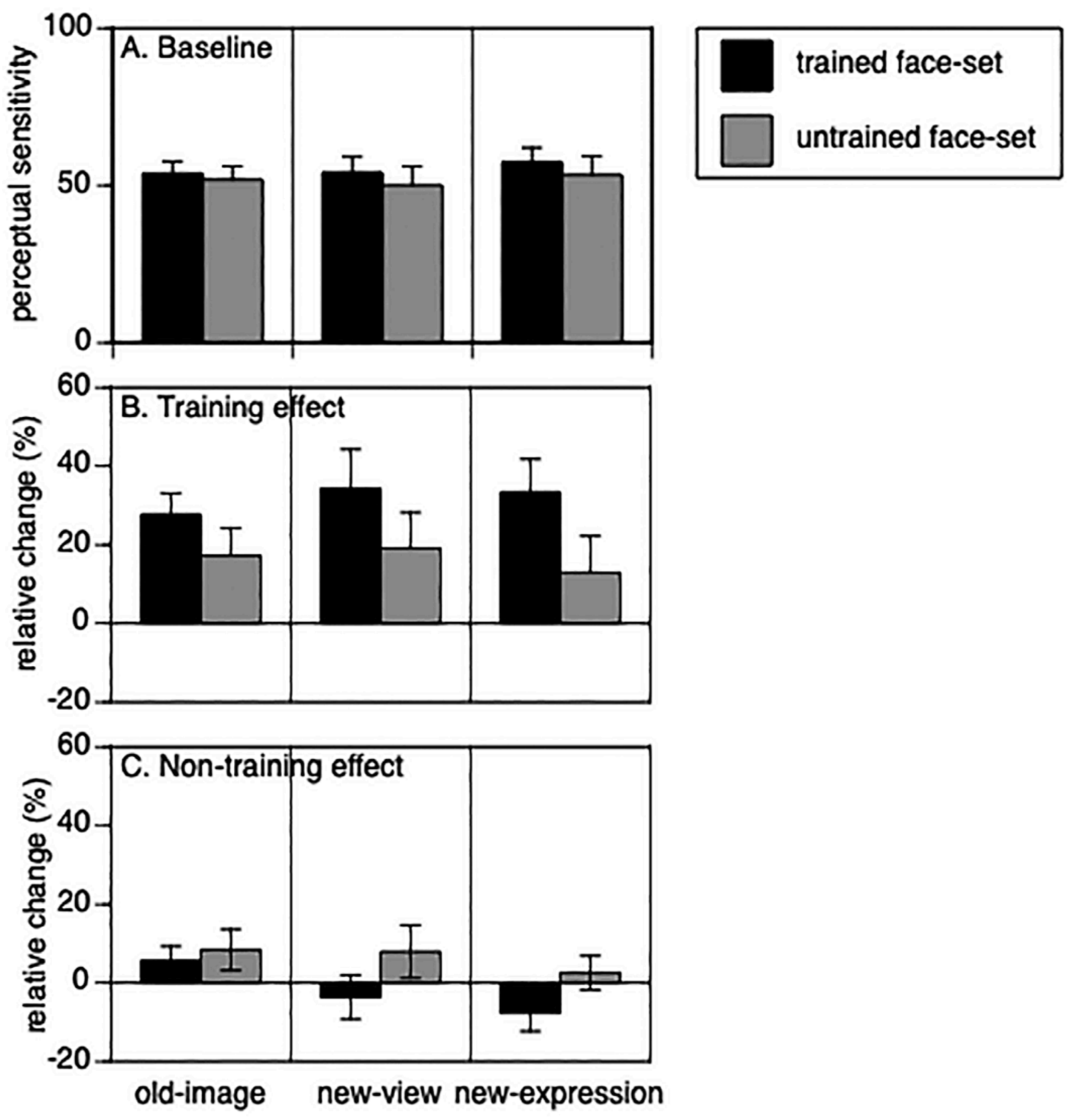

Figure 5. Overall Results. A) Baseline performance. Perceptual sensitivity is shown for the three test conditions for the trained and untrained faces. There is no difference between the trained and untrained faces, or between the old-image and new-view conditions, but the new-expression condition is more difficult than the old-image condition. B) Mean relative change in perceptual sensitivity after training for the three test conditions. C) Mean relative change after the non-training periods. D) 
Training effects as in B, for mean absolute change in perceptual sensitivity. E) Non-training effects as in $C$, for mean absolute change. Error bars show one standard error. In all, a positive change indicates better perceptual sensitivity.

The ANCOVA of the absolute change scores, with average baseline performance on all 12 tests included as a covariate, showed a marginal effect of intervention $\left(\mathrm{F}_{(1,8)}=5.146, \mathrm{p}=.053\right)$, again with a large effect size $\left(\eta^{2}=.391\right)$. Interestingly, this was not qualified by an intervention $\mathrm{x}$ baseline average interaction, suggesting that baseline performance did not have a significant effect on whether or not participants showed improvement from training.

Finally, in the 'first-phase ANOVA' we examined the absolute change in perceptual sensitivity for just the first phase of the study to compare the training period of those who trained first (free period control), with the non-training period of those who completed the TV control. Likely due to the small sample sizes for this analysis, there were violations of normality for the untrained, new view and untrained, new expression faces, only for those who trained first. After applying a square root transformation, there were three remaining extreme outliers, two in the train first group and one in the TV control group, which were winsorized to be .01 more extreme than the nearest score for that group. In each case, these changes were against the direction of our hypothesis in that the two outliers in the trained group were made to be less improved and the one outlier in the TV control group was made to be closer to 0 absolute change (they were originally showing a decrease in performance after the TV control). After this transformation, there were no remaining extreme outliers and only a small violation of normality for the TV control group in the untrained, old view condition (Shapiro Wilk's $p=.04$ ). As ANOVA is rather robust to small violations of normality, we proceeded with the analysis. Once again, we observed a significant effect of intervention $\left(\mathrm{F}_{(1,8)}=6.857, \mathrm{p}=.03\right)$, again with a large effect size $\left(\eta^{2}=.462\right)$, suggesting that those who completed the training program $(\mathrm{M}=13.65$, S.E. $=2.978$, untransformed) showed greater improvement that those who completed the TV control $(\mathrm{M}=2.535$, S.E. $=2.978$ untransformed).

We also assessed changes at an individual subject level, by asking if interventions changed the mean performance for the 12 online tests (Figure 6). Training increased perceptual sensitivity in eight of ten subjects, with a trend in one other. Perceptual sensitivity increased after the control television 
task in one of the five subjects who did the control task first. Sensitivity also continued to increase in the free period after training in one of the five subjects who did training first, with a trend in another.
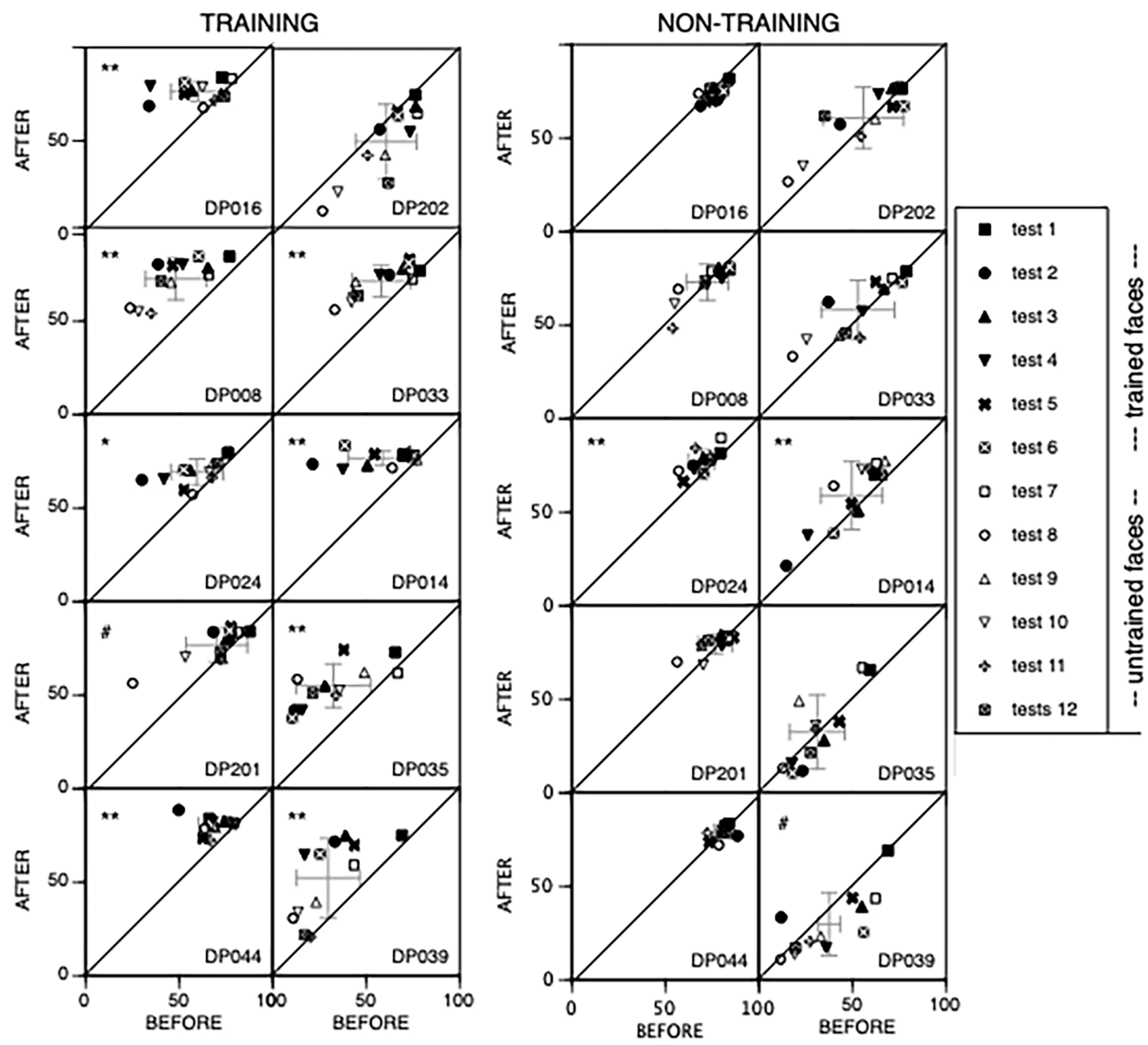

Figure 6. Perceptual sensitivity on the 12 on-line assessments, for each subject. In each set of graphs, those in the left column are for subjects who did training first, while those in the right column are for those who did the control television task first. Left set of graphs show performance after training plotted against results before training. Right set of graphs show performance after versus before the non-training period: for those subjects in the left column, this would be the free period, whereas for those subjects in the right column, this would be the control television task. Solid black 
symbols are for the trained face-set, and clear symbols for the untrained face-set. Points above the diagonal lines correspond to better perceptual sensitivity after the intervention. For each subject the mean perceptual sensitivity for all 12 tests is indicated by the large grey crosses, whose arms show one standard deviation. Symbols in top left corner of each graph indicate the significant of the change in mean perceptual sensitivity for that subject (\#0.05<p<0.10,*0.01<p<0.05, **p<0.01).

\section{Did the improvements generalize to new viewpoints and expressions?}

This would be reflected in the effects of training on the new-view and new-expression testing conditions for the trained faces. In the general ANOVA, there was no interaction between intervention and testing condition $\left(\mathrm{F}_{(2,8)}=1.93, \mathrm{p}=.21, \eta^{2}=.326\right)$. However, in the ANCOVA, when baseline performance was included as a covariate, there was an interaction between intervention and testing condition $\left(\mathrm{F}_{(2,7)}=5.064, \mathrm{p}=.044, \eta^{2}=.591\right.$; Figure 7$)$. Tests of simple main effects revealed no differences between the old-image, new-view, and new-expression conditions after the training period ( $p$ > 39 for all three comparisons). Conversely, for the non-training period, there were marginally significant differences between the old-image and new-expression testing conditions $(\mathrm{p}=.056)$ as well as between the new-view and new-expression conditions $(\mathrm{p}=.072)$. This suggests that while the newexpression condition (which contained deviation in both viewpoints and expression from the target face) was the most challenging of the three after the non-training period, the addition of novel viewpoints and expression did not present the same challenge after the training period. 


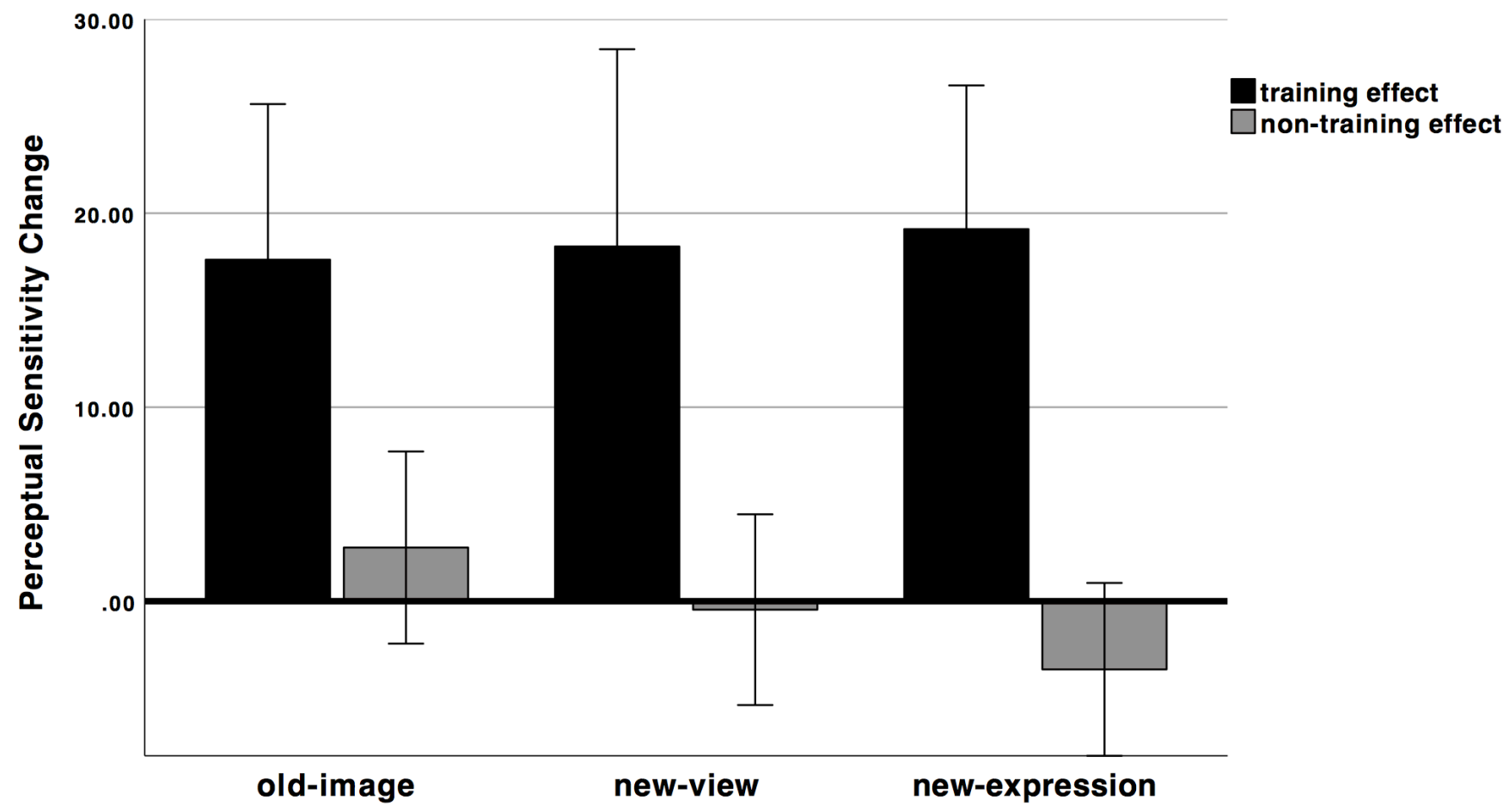

Covariates appearing in the model are evaluated at the following values: BaselineAvg $=53.4438$ Error bars: $95 \% \mathrm{Cl}$

Figure 7. Generalization to new view and expressions of trained faces. The black bars show the change in perceptual sensitivity for the training period. The grey bars represent the change during the non-training period. Data are presented separately for the three testing conditions: old-image, newview, and new-expression when baseline performance had been included as a covariate. The error bars indicate the 95\% confidence intervals for each condition.

The first-phase ANOVA, which did not include baseline as a covariate, produced no intervention $\mathrm{x}$ testing condition interaction $\left(\mathrm{F}_{(2,7)}=1.24, \mathrm{p}=.347, \eta^{2}=.261\right)$.

To further explore the generalization to new viewpoints and expressions in trained faces, planned comparisons with paired-samples t-tests were conducted to examine if novel viewpoints and expressions were better recognized in the training vs non-training periods. There was a significant difference between training and non-training periods for both the new-view tests (training $\mathrm{M}=18.29$, s.d. $=15.55$; non-training $\mathrm{M}=-.44$, s.d. $=7.4 ; \mathrm{t}_{(9)}=3.286, \mathrm{p}=.009$, cohen's $\left.\mathrm{d}=.965\right)$ and the newexpression tests (training $\mathrm{M}=19.18$, s.d.=12.81; non-training=-3.51, s.d. $=6.55 ; \mathrm{t}_{(9)}=4.47, \mathrm{p}=.002$, cohen's $\mathrm{d}=1.41$ ). Thus, these results provide strong evidence for the generalization of training-induced 
improvements in the perception of facial identity to new views of learned faces and new expressions of those faces.

\section{Did the improvements generalize to new identities?}

In the general ANOVA, there was an interaction between intervention and face-set $\left(\mathrm{F}_{(1,9)}=14.39, \mathrm{p}\right.$ $\left.=0.004, \eta^{2}=.615\right)$. A priori linear contrasts showed that the training effect was greater than the nontraining effect for trained faces (training period $\mathrm{M}=18.36$, s.e.=3.47; non-training period $\mathrm{M}=-.39$, s.e. $\left.=1.53, \mathrm{~F}_{(1,9)}=15.67, \mathrm{p}=0.003, \eta^{2}=.635\right)$ but not for untrained faces (training period $\mathrm{M}=8.34$, s.e.3.36, non-training period $\mathrm{M}=4.38$, s.e. $\left.=2.01 ; \mathrm{F}_{(1,9)}=.8, \mathrm{p}=0.394, \eta^{2}=.082\right)$. In the ANCOVA, the intervention by face set interaction was not significant $\left(\mathrm{F}_{(1,8)}=1.874, \mathrm{p}=.208, \eta^{2}=.190\right)$. Finally, like the general ANOVA, the first-phase only ANOVA (for which the transformation described above was applied) revealed a significant intervention by face part interaction $\left(F_{(1,8)}=17.11, p=.003, \eta^{2}=.681\right)$. Once again, planned linear contrasts showed that, for trained faces, the change in perceptual sensitivity was greater during the training $(\mathrm{M}=18.22$, s.d. $=8.33$, untransformed $)$ than the TV control task $(\mathrm{M}=-.01$, s.d.=6.16, untransformed; $\mathrm{F}_{(1,8)}=12.565, \mathrm{p}=.008, \eta^{2}=.61$, transformed). However, for untrained faces, there was no difference between the training period $(\mathrm{M}=9.09$, s.d. $=8.48$, untransformed $)$ and TV control period $\left(\mathrm{M}=5.08\right.$, s.d.7.81, untransformed; $\mathrm{F}_{(1,8)}=.08, \mathrm{p}=.783, \eta^{2}=.01$, transformed $)$.

\section{For those who trained first, did the benefits of training maintain over the three-month 'free- period'?}

In the five subjects who did training first, perceptual sensitivity improved from a baseline of 61.42 $($ s.d. $=8.73)$ to an average of 75.07 (s.d. $=4.32)$ immediately after the training period. This benefit remained even after the 3 month free-period, with a perceptual sensitivity of 76.52 (s.d. 2.9). The difference between perceptual sensitivity immediately after training and immediately after the freeperiod was not significant $\left(\mathrm{t}_{(4)}=-.81, \mathrm{p}=.462\right.$, cohen's $\mathrm{d}=.36$; Figure 8$)$, suggesting that the benefits gained during the training period were maintained during the free-period. 

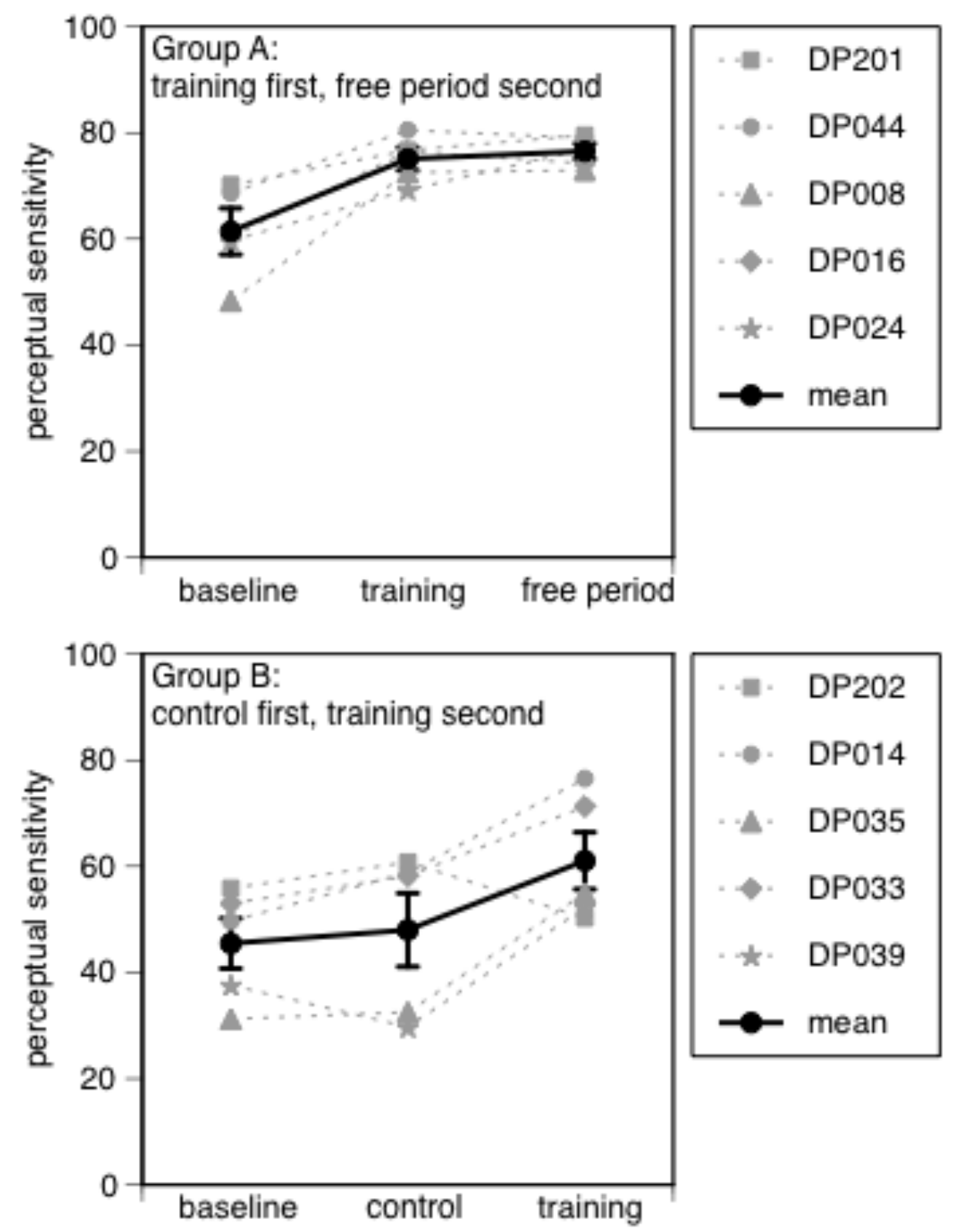

Figure 8. Maintenance. In both graphs, dashed lines and grey symbols show perceptual thresholds of individual subjects, black lines show the group mean, with error bars indicating one standard error. In Group A, the five subjects who did the training task first, performance improves from baseline after training with no significant decline after 3 months of a free period without any intervention. In Group $B$, the five subjects who did the control television task first, there is no improvement during the control period, but improvement after training.

\section{b. Secondary outcomes.}


Across all subjects, there was a trend for training to increase scores on the Cambridge Face Memory Test by a mean of 4.3 (s.d. $\left.6.25, \mathrm{t}_{(9)}=2.17, \mathrm{p}=0.058\right)$. For the five subjects who completed the TV control task first, there was no significant improvement in CFMT scores $(M=9.6$, s.d. $=12.26$, $t(4)=1.75$, $\mathrm{p}=.155)$. Scores on the face component of the Warrington recognition Memory Test increased after training by $5.0\left(\right.$ s.d. $\left.6.0, \mathrm{t}_{(9)}=2.64, \mathrm{p}=0.027\right)$. For the 5 subjects in the TV control, there was no significant improvement in Warrington scores $(\mathrm{M}=.8, \mathrm{~s} . \mathrm{d} .=4.6, \mathrm{t}(4)=.39, \mathrm{p}=.717)$. As this was the only secondary measure that showed a significant improvement, we conducted an a posteriori analysis to see if those who trained first maintained this improvement over the 3-month free-period. There was a significant effect of testing period $\left(F(1,4)=22.86, p=.009, \eta^{2}=.851\right)$ with participants showing an improvement over their baseline score both immediately after training $(p=.02)$ and after the free-period $(\mathrm{p}=.009)$, however, there was no difference between scores immediately after training and after the free-period ( $\mathrm{p}=1.0$; Figure 9.). The lack of difference between post-training and post-free-period suggests that participants maintained their improvement even during the 3-months after the training ended. Finally, scores on the Cambridge Face Perception Test did not change after training (mean 0.60, s.d. $\left.7.4, \mathrm{t}_{(9)}=0.26, \mathrm{p}=0.80\right)$, nor during the TV control task $(\mathrm{M}=-7.8$, s.d. $=7.67, \mathrm{t}(4)=-2.28, \mathrm{p}=.085)$.

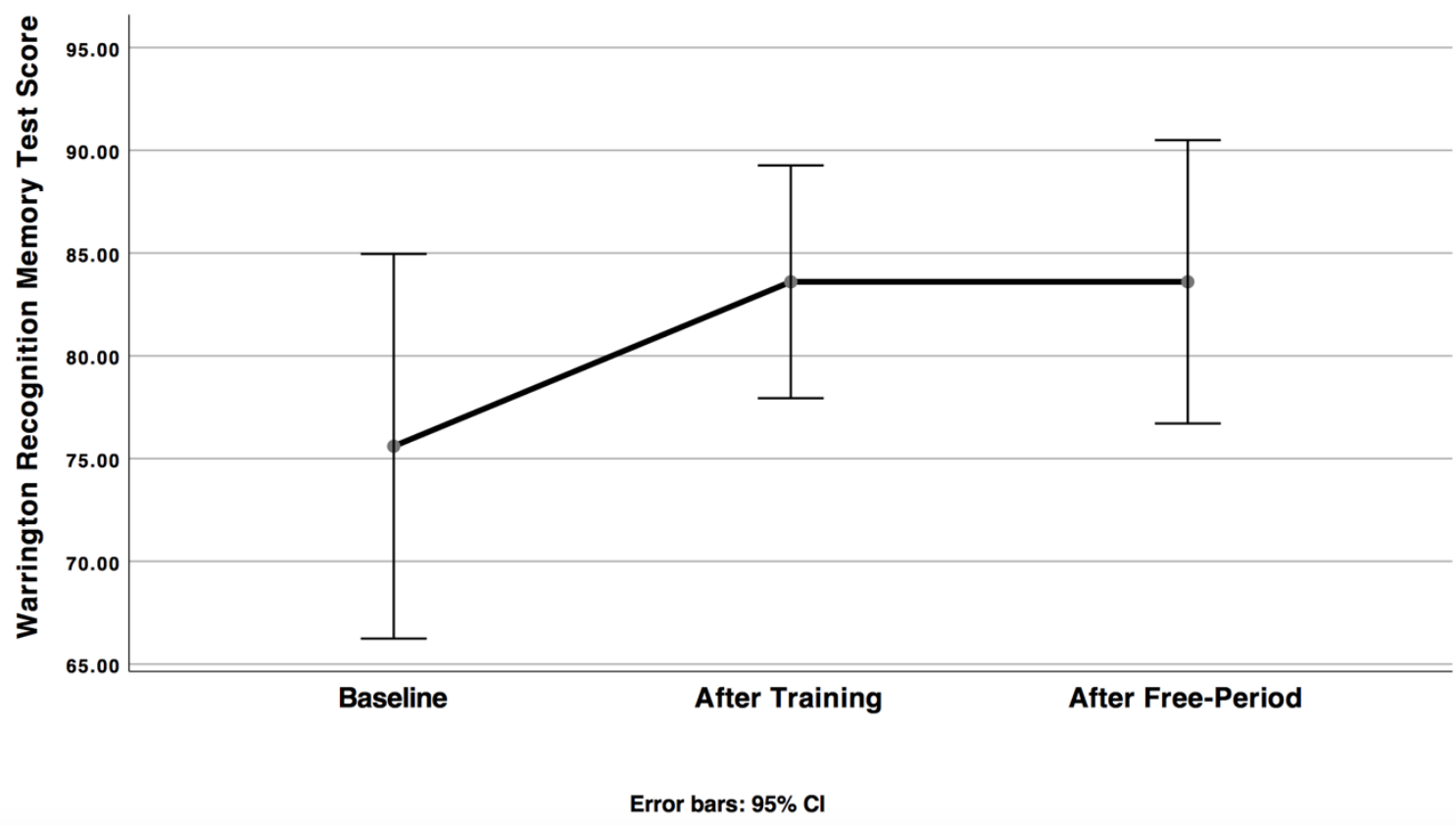

Figure 9. Maintenance of improvement on the Warrington. Data are presented for the train-first group, showing an improvement in Warrington Recognition Memory Test scores between baseline and post-training assessments, which are then maintained without further improvement during the freeperiod. Error bars represent 95\% confidence intervals for each testing period. 


\section{c. Impact of subject variables.}

There was a correlation of the mean training effect with age $\left(r=0.71, F_{(1,9)}=9.27, p<0.015\right)$. This could not be attributed to an age-related difference in severity, as age correlated with neither the mean perceptual sensitivity $(r=0.07)$ nor the baseline score on the Cambridge Face Memory Test $(r=0.008)$. Underlining this, the global training effect did not correlate with baseline scores on the PI20 questionnaire $(r=0.27)$, the Cambridge Face Memory Test $(r=-0.21)$, the face component of the Warrington Recognition Memory Test $(\mathrm{r}=0.21)$, or the Cambridge Face Perception Test $(\mathrm{r}=.16)$.

d. Subjective reports. Our subjects varied widely in how they felt training changed their daily experience with faces afterwards, ranging from unimpressed (e.g., DP016) to wildly enthusiastic (e.g., DP044): their descriptions are provided in the Supplement.

\section{e. Comparison with the study of acquired prosopagnosia (Davies-Thompson et al., 2017).}

Average baseline perceptual sensitivity for the developmental prosopagnosia group was 0.53 (s.d. 0.12 ), which was greater than the mean of 0.40 (s.d. 0.12) for our acquired prosopagnosic cohort, $\left(\mathrm{t}_{(9)}=\right.$ $2.66, \mathrm{p}<0.027$ ). Thus the developmental prosopagnosic subjects began with better perception of faces. The mean relative change in perceptual sensitivity from training was $24 \%$ (s.d. 22) for developmental prosopagnosia versus 39\% (s.d. 22) for acquired prosopagnosia, though this did not differ statistically $\left(\mathrm{t}_{(10)}=1.60, \mathrm{p}=0.14\right)$. The mean absolute change from training was more similar between the two groups, 0.13 (s.d. 0.10) for developmental prosopagnosia versus 0.17 (s.d. 0.07) for acquired prosopagnosia $\left(\mathrm{t}_{(10)}=0.89, \mathrm{p}=0.39\right)$.

\section{DISCUSSION}

We found that a training program using a perceptual learning approach improved perceptual sensitivity for faces in developmental prosopagnosia. The effects generalized to new views and new expressions of the trained faces and persisted for at least three months. The magnitude of improvement was less for untrained faces. There was some improvement on standard neuropsychological tests of short-term face familiarity, and several subjects provided qualitative reports of experiences suggesting improved face recognition in daily life. 
As with our prior study, the control television task did not result in improved perceptual sensitivity in the five subjects who did this task before face training. This suggests that the benefits of training cannot be attributed to general factors such as study engagement, attention to faces and interactions with the examiner. The blinding of examiners administering and scoring tests guarded against experimenter biases, but given that it was not possible to blind subjects to whether they were training or doing a control task, we cannot exclude a potential influence of the expectations of subjects regarding training (Younger, Gandhi, Hubbard, \& Mackey, 2012).

Whether effects generalize to new views of trained faces is not only an important issue for ecological validity but can also inform us about the type of processing at which learning is occurring. Generalization suggests that learning is operating on three-dimensional expression-invariant representations, rather than lower-level image processing. In prior studies of developmental prosopagnosia the compensatory strategy of explicitly attending to features showed delayed generalization to new views in subjects K (L. Schmalzl, R. Palermo, M. Green, R. Brunsdon, \& M. Coltheart, 2008), AL (Brunsdon et al., 2006), and to new identities in LG (Pizzamiglio et al., 2017). Among remedial approaches, repeated training of TM to recognize his mother did not transfer to new views (Dalrymple, Corrow, Yonas, \& Duchaine, 2012), and training the ability to see the spatial relations between the features of faces seen in frontal view did not improve the performance of 24 developmental prosopagnosics on perceptual tests that show faces in other views (J. DeGutis et al., 2014). Our perceptual learning approach in acquired prosopagnosia did show strong generalization to both new views and new expressions (Davies-Thompson et al., 2017). The current study replicates this finding in developmental prosopagnosia. This may reflect the explicit emphasis on discrimination across viewpoint and expression variations in the design of our training program.

The transfer of training benefits to new faces would indicate acquisition of a new perceptual skill, while its absence might imply that any benefit is due to over-learning of a stimulus set with existing skills. Over-learning can be useful for a set of important, frequently encountered faces, but skill development is more useful for daily life. One single-case study in developmental prosopagnosia did not find that explicit attention to features improved face recognition with a new set of faces (Brunsdon et al., 2006). However, another single-case study that emphasized focus on the eyes did report generalization to new faces (familiar and unfamiliar) after training with an unfamiliar face set (Pizzamiglio et al., 2017). Some of 24 subjects with developmental prosopagnosia in another training study showed indirect evidence of transfer, insofar as perceptual learning improved performance on 
standard tests of face processing, which naturally use faces other than those used in training (J. DeGutis et al., 2014; J. M. DeGutis et al., 2007). Our prior study with the current training program in acquired prosopagnosia showed good evidence of transfer to new faces. In the current study of developmental prosopagnosia the evidence for transfer was more marginal statistically, which may reflect a smaller training effect size and less severe perceptual deficit in developmental prosopagnosia.

We also found modest improvements on other face tests, most notable a mean increase of 5 points on the face component of the Warrington Recognition Memory Test, which represents $10 \%$ of the maximum score of 50 (or $20 \%$ of the difference between chance and the maximum score), and a trend to improvement on the Cambridge Face Memory Test. Some consider that improved scores on these standard neuropsychological tests of face familiarity are also evidence of transfer (J. DeGutis et al., 2014). Benefit in daily life would also be evidence of transfer as well as ecological validity. While we did not quantify this, our subjects provided qualitative accounts of their daily experience with faces after training, with some detailed anecdotes suggesting improved face recognition.

Maintenance of benefit beyond the period of training is desirable, though a benefit that requires reinforcement by occasional practice could still be helpful. As we had reviewed (Davies-Thompson et al., 2017), maintenance has only been assessed sporadically in the past, at intervals ranging from minutes (Polster \& Rapcsak, 1996) to weeks (Bate et al., 2015; J. M. DeGutis et al., 2007; Francis et al., 2002; L. Schmalzl et al., 2008) to months (Brunsdon et al., 2006; De Haan et al., 1991; J. M. DeGutis et al., 2007) and rarely years (C. E. Wilson, Palermo, Schmalzl, \& Brock, 2010). In our prior study of acquired prosopagnosia we found no decline in benefit in the three months after training, when subjects who had trained first were engaged in the control television task (Davies-Thompson et al., 2017). The current study replicates this maintenance of benefit and shows that the control task is not necessary for maintenance, as the subjects who trained first had simply returned to their usual activities during the three months that followed.

One question is whether training efficacy varies with subject-related factors (Bate \& Bennetts, 2014; J. M. DeGutis et al., 2014). Some speculate that there may be a U-shaped function for age, with more rehabilitative potential in childhood and less in older adults (Bate \& Bennetts, 2014). However, we found if anything a modest positive correlation with age. While this finding requires caution and desires replication, particularly given the modest size of our sample, it suggests at the very least that older as well as younger adult subjects can benefit from training. 
Is it possible that participants simply improved at the training task, rather than improving at face processing in particular? There are a few reasons to suggest that this is not the case. First, if participants improved only at the task and not in their face processing skill, then they should also have shown equal improvement in the recognition of novel images of learned faces and images of new identities. However, improvement was much more modest for untrained faces than trained faces, suggesting that the generalization to novel viewpoints and expressions of trained faces was genuine. In addition, if participants were improving only at the task itself, and not in their face processing ability, we would not have expected to observe improvements in the Warrington Recognition Memory Task, as this task uses an old/new paradigm, rather than the 2-alternative-forced-choice method of the training program.

While the improvements shown in the present study are encouraging, our study is not without limitations. One challenge to studies of this nature is the recruitment of subjects with prosopagnosia. The nearly 7-month minimum commitment required to complete the full training program limited the number of participants able to complete this in-person study. Due to small sample size, our analysis did not include a correction for type I error. However, supporting evidence of a training effect, we find rather large effect sizes. Regardless, a posteriori analyses without correction for type I error, ought to be taken with consideration. Future work should consider a completely online approach with perhaps a shorter time commitment in order to recruit a larger sample. A second consideration of the present study is the nature of the control task. Our primary goal was to assess the utility of a perceptual learning approach to training. Therefore, the TV control required participants to watch an assigned television show and answer questions about the episodes. This control ensured that the experimental and control conditions offered a similar amount of exposure to faces, while differing in the perceptual learning approach. This is particularly important because many of our participants, anecdotally, avoid exposure to faces (or watching TV) due to the difficulty in recognizing others (or following the plot) when the individuals cannot be reliably recognized. Similarly, it controlled for exposure to face tests, interactions with the experimenters, and general hyperawareness of face processing that comes with participation in this type of study. Nonetheless, future studies might ask whether the training benefit is specific to faces by opting for a control task in which participants complete a perceptual learning control task, using objects other than faces.

While improvements shown in the current study are interesting, a remaining question is why participants with prosopagnosia would improve using this perceptual learning paradigm. Previous 
studies have investigated the nature of the impairment in developmental prosopagnosia, demonstrating that subjects with prosopagnosia have impairments in the holistic processing of faces (Galia Avidan, Tanzer, \& Behrmann, 2011; Joseph DeGutis, Cohan, Mercado, Wilmer, \& Nakayama, 2012; Kimchi, Behrmann, Avidan, \& Amishav, 2012). Thus, one approach has been to specifically train the mechanisms underlying holistic processing (J. DeGutis et al., 2014). However, others have argued against impairments in holistic processing, at least under certain testing conditions (Biotti et al., 2017), or emphasized that the specific impairment varies widely across individuals (Le Grand et al., 2006; Lee, Duchaine, Wilson, \& Nakayama, 2010). Thus, our training program intentionally makes no assumption about what, in particular, needs to be trained for a particular person. The advantage of this approach is that it places demand on the face processing system by gradually increasing the similarity of faces. Thus, any particular aspect of facial processing that needs to be trained (e.g. holistic processing, attention to the eyes, etcetera) should be increasingly challenged within each training session, at a level appropriate to the individual, for configural, local, or holistic aspects of faces. Because we did not choose to target one particular aspect of facial cue to identity, this approach does not, tell us why people improved with training.

Similarly, it is not clear if participants have improved at a remedial level in which their face processing mechanisms (both cognitive and neural) now model those without prosopagnosia, or if the training has produce compensatory strategies. At a neural level, it is not clear if participants are improving because the efficiency of their face-network has been improved or because they have recruited non-face neural mechanisms for the recognition of faces. While both the acquired and developmental prosopagnosic subjects improved with this training program, it is not clear if either group benefitted due to the improved efficiency of existing components of the neural face network or to recruitment of non-face areas. Future research should examine the relationship of training benefit and changes in functional activity of face and non-face areas of the brain.

In summary, our results show that perceptual learning can enhance perceptual discrimination of faces in subjects with developmental prosopagnosia, just as it does in acquired prosopagnosia (DaviesThompson et al., 2017), and that this is an effect that persists for at least several months. The effects generalize to different viewpoints and expressions, indicating learning at the level of three-dimensional expression-invariant facial representations. Evidence of transfer to untrained faces was more modest than that seen for acquired prosopagnosia, but this did include some improvement on standard neuropsychological tests of face memory. At least some subjects reported benefits in their daily life. 
While the current training program is not a cure for prosopagnosia, the results show that perceptual sensitivity for faces can be improved in subjects with the developmental variants of prosopagnosia, just as it can in the acquired form. It is our hope that this evidence will motivate future training studies that will advance from these initial results. 
ACKNOWLEDGEMENTS: We thank J DeGutis and B Duchaine for helpful discussion, Noland Germain for his programming skills, and the subjects for the considerable time and effort they gave. This work was presented in part at the European Conference on Visual Perception, Barcelona, Aug 2016 and the Vision Sciences Society, St. Petersburg Beach, May 2017.

FUNDING: This study was supported by grant MOP-102567 from the Canadian Institutes of Health Research and grant 228984 from the Canadian Foundation for Innovation. JB was supported by a Canada Research Chair 950-228984 and the Marianne Koerner Chair in Brain Diseases. SC was supported by National Eye Institute award F32 EY023479-02. The content is solely the responsibility of the authors and does not necessarily represent the official views of the National Institutes of Health. 


\section{Supplement: Subjects' reports of the effects of training on daily life.}

DP008 (absolute training benefit 24\%) - My short-term memory for faces, for example, when I go to party. The training has lead to more confidence. This short-term memory thing has really helped me. I have a different way of looking at faces than I used to. I am looking at the face more and I look longer, and at different parts. However, my long-term memory for faces is still not great.

DP014 (absolute training benefit 18\%) - I've been reading a few very interesting books on neuroplasticity over the past few months, and I'm starting to understand just how much potential this program has, provided the difficulty starts at the right level and increases at the right rate. I feel like some people might need more and less hours of practice than others, but I have plenty of personal experiences suggesting that this is working for me...All my life I've been approaching the problem wrong - I've been avoiding situations where facial recognition is essential and I've been compensating with other means of recognizing people, thus allowing my limited facial recognition skills to remain at a very low level.

DP016 (absolute training benefit 16\%) - I found the training to be very useful and believe that my participation provided me with a greater perspective of the facial recognition challenges I face and ways to try to minimize those challenges. While the training itself did not eliminate my facial recognition challenges, I feel that I am more aware of variations in people's faces and trying to associate those variations with particular people.

Unfortunately, even on the rare occasion when I do recognize someone outside my normal circle, I still struggle with attaching/recalling what I know about that person with their face. My go to is usually voice and body language as I search my brain for what I know about a person but that data is always limited compared to what I should be able to recall.

DP024 (absolute training benefit 9\%) - I have developed new tricks for recognizing faces, but I am not sure if they are normal or not. I still look mostly at eyebrows and eyes to recognize someone. I feel like I know the faces that I trained on well, but I am not sure it generalized to new faces . . I'm not sure. It's hard to tell if the training has had an effect on my face recognition in real life. I work in a very small office and at home. 
DP033 (absolute training benefit 13\%) - Watching the series Once Upon a Time - it's hell because the characters exist in different timelines, with different hair and clothing styles, but (my husband) helps me. And then they introduce a new character, a wicked witch in green make up. "Hey!" says me, "Is that Charlotte from Lost?” And it was. Her long red hair probably helped, though.

Also a co-worker came to my sword salle while I was training, just dropped in and called me by name. I figured out it was him really fast - happy.

DP035 (absolute training benefit 22\%) - At first I felt like it wasn't helping and it was difficult to keep going. The last time (my wife) and I went for a walk I was able to recognize more people than she did... which is odd, so I guess it is helping :) Then, the other night I had a dream that I could recognize people by their faces. The dream was sort of a realization, like "wow, I can do that now". It feels good.

DP039 (absolute training benefit 22\%) - I did feel like I had improved in terms of my everyday experiences. To begin, I found myself feeling more confident in general, but also in terms of recognizing people. I stopped shying away from walking up to people I "thought" I might know, and found the courage to actually approach people and smile at them. When I didn't know the person, I would say "you remind me of someone I know and I always smile when I think about them." On the occasions when I actually got the right person, it was a joyful experience. To be able to walk up to someone (having my condition) and not shake and worry was amazing enough, but to actually get the right person was a miracle. I thought after all that training that I would never want to identify faces again but, what it actually did was help me with my self-confidence and lessen some of the burden I carry as a person living with Social Anxiety, a diagnosis I only knew about after you submitted your paper in Barcelona.

I still do get some faces wrong, but I'm not that worried about it now. I think the biggest thing was identifying that, first, I had prosopagnosia (which I didn't even know as a term prior to contacting you) and then realizing and understanding that I suffered from social anxiety. Now that I know what I am dealing with, I am taking steps to alleviate much of the angst and timidity that I feel each day simply walking around my city.

The study brought a lot of amazing insights, some challenges, a few tears (to be honest), and more life to my life. I really hope that the study continues forever, because the more I see people with social anxiety I can't help but wonder if they are not suffering like I used to. And let me emphasize "used to," because while I still do have some social anxiety, it's not the way it used to be. I was paralysed by my anxiety 
because I didn't know where it was coming from. A lot of psychiatrists couldn't figure it out either.

Counselors have tried to fix it, but were unsuccessful. So now at least I have a starting point. Sadly most of these mental health professionals still don't know anything about Prosopagnosia but they will. And then life will be better for everyone.

DP044 (absolute training benefit 12\%) - Remember when you asked during my last visit what the impact of the face training had been in my life, and I gave a bit of a wishy-washy answer to the effect of "it's hard to say because my life and the demands on me now are so different than they were before?" Well, events have been piling up and I feel compelled to update you so that you can have a fuller picture of what's happened. I might have told you before that I rarely ran into people I know on the street, and I thought that was due to a failure to recognize people I know out of context; I've lived here for such a long time that I know a lot of people and should run into acquaintances with some regularity. Well, recently, I find myself recognizing a WHOLE BUNCH of people on the street, way out of context. And the best part is that I'M recognizing THEM and initiating contact! Twice, I saw people I know while I was driving and they were walking along the street. One of those instances occurred today and the only reason I didn't roll down my window to yell "hi!" was because they were hurrying across the street with their child and trying to make it before the light changed. Another time I ran into someone while we were crossing the street in opposite directions and recognized her right away even though I hadn't seen her in a long time. I've also been watching new-tome movies and having less trouble recognizing characters in different scenes (and therefore less trouble with following story lines). All of this has helped me feel a lot more confident about being able to recognize people and I feel like a fog, or cloud, has been lifted and I'm seeing the world (of faces) with new eyes. Thus, my updated report on the impact of the face training on my life is that it has had a huge impact in a positive way, and I'm excited to see what else will unfold in my life with my greatly-improved face recognition apparatus!!

$* * *$

I wanted to thank you (again!) for the difference that you have made in my life- I have many more stories about people I've recognized and how the fact that I recognized them made the subsequent interactions that much better. I even have a story about being able to tell two very similar-looking people apart...all of this to say that it is not an exaggeration to say that your training program has changed my life, and I trust that your research will continue to transform lives. 
DP201 (absolute training benefit 6\%) - The training helped me to know where I was supposed to be looking and make me faster at that process. I haven't noticed a difference in my everyday life, but I also am working from home in a completely new city. I feel like I have improved at what the task was asking me to do, but I was always working really hard at it. It helped me to look at new things, like noses ... I never thought to look at noses before.

DP202 (absolute training benefit -10\%) - I become more aware of the techniques that I use and I have refined those techniques, but 9 times out of 10, I feel like it doesn't help me that much. I don't really feel like I have improved, but bits of a foundation are coming together. I think I am better able to visualize what people look like. I've found that I can imagine what Donald Trump looks like now and I am better at remembering what specific features look like. 


\section{REFERENCES}

Ahissar, M., \& Hochstein, S. (2004). The reverse hierarchy theory of visual perceptual learning. Trends Cogn Sci, 8(10), 457-464. doi:10.1016/j.tics.2004.08.011

Avidan, G., \& Behrmann, M. (2009). Functional MRI reveals compromised neural integrity of the face processing network in congenital prosopagnosia. Curr Biol, 19(13), 1146-1150. doi:S09609822(09)01059-8 [pii]

10.1016/j.cub.2009.04.060

Avidan, G., Tanzer, M., \& Behrmann, M. (2011). Impaired holistic processing in congenital prosopagnosia. Neuropsychologia, 49(9), 2541--2552.

Baeck, A., Windey, I., \& Op de Beeck, H. P. (2012). The transfer of object learning across exemplars and their orientation is related to perceptual similarity. Vision Res. doi:S0042-6989(12)00202-7 [pii]

10.1016/j.visres.2012.06.023

Ball, K., \& Sekuler, R. (1987). Direction-specific improvement in motion discrimination. Vision Research, 27(6), 953-965.

Baron-Cohen, S., Wheelwright, S., Skinner, R., Martin, J., \& Clubley, E. (2001). The Autism-Spectrum Quotient (AQ): Evidence form asperger syndrome/high-functioning autism, males and females, scientists and mathematicians. Journal of Autism and Developmental Disorders, 31(1), 5--17.

Barton, J., Press, D., Keenan, J., \& O'Connor, M. (2002). Lesions of the fusiform face area impair perception of facial configuration in prosopagnosia. Neurology, 58, 71-78.

Barton, J. J., \& Corrow, S. L. (2016). The problem of being bad at faces. Neuropsychologia, 89, 119-124.

Barton, J. J., \& Corrow, S. L. (2016). The problem of being bad at faces. Neuropsychologia, 89, 119-124. doi:10.1016/j.neuropsychologia.2016.06.008

Bate, S., Bennetts, R., Mole, J. A., Ainge, J. A., Gregory, N. J., Bobak, A. K., \& Bussunt, A. (2015). Rehabilitation of face-processing skills in an adolescent with prosopagnosia: Evaluation of an online perceptual training programme. Neuropsychol Rehabil, 25(5), 733-762. doi:10.1080/09602011.2014.973886

Bate, S., \& Bennetts, R. J. (2014). The rehabilitation of face recognition impairments: a critical review and future directions. Front Hum Neurosci, 8, 491. doi:10.3389/fnhum.2014.00491

Bate, S., Cook, S. J., Duchaine, B., Tree, J. J., Burns, E. J., \& Hodgson, T. L. (2014). Intranasal inhalation of oxytocin improves face processing in developmental prosopagnosia. Cortex, 50, 55-63. doi:10.1016/j.cortex.2013.08.006

Beyn, E. S., \& Knyazeva, G. R. (1962). The problem of prosopagnosia. J Neurol Neurosurg Psychiatry, 25, 154-158.

Biotti, F., Wu, E., Yang, H., Jiahui, G., Duchaine, B., \& Cook, R. (2017). Normal composite face effects in developmental prosopagnosia. Cortex, 95, 63-76.

Brunsdon, R., Coltheart, M., Nickels, L., \& Joy, P. (2006). Developmental prosopagnosia: A case analysis and treatment study. Cogn Neuropsychol, 23(6), 822-840. doi:10.1080/02643290500441841

Dalrymple, K. A., Corrow, S., Yonas, A., \& Duchaine, B. (2012). Developmental prosopagnosia in childhood. Cogn Neuropsychol, 29(5-6), 393-418. doi:10.1080/02643294.2012.722547

Dalrymple, K. A., Fletcher, K., Corrow, S., das Nair, R., Barton, J. J., Yonas, A., \& Duchaine, B. (2014). "A room full of strangers every day": the psychosocial impact of developmental prosopagnosia on children and their families. J Psychosom Res, 77(2), 144-150. doi:10.1016/j.jpsychores.2014.06.001

Dalrymple, K. A., \& Palermo, R. (2016). Guidelines for studying developmental prosopagnosia in adults and children. Wiley Interdiscip Rev Cogn Sci, 7(1), 73-87. doi:10.1002/wcs. 1374 
Davies-Thompson, J., Fletcher, K., Hills, C., Pancaroglu, R., Corrow, S. L., \& Barton, J. J. (2017). Perceptual Learning of Faces: A Rehabilitative Study of Acquired Prosopagnosia. J Cogn Neurosci, 29(3), 573-591. doi:10.1162/jocn a 01063

Davies-Thompson, J., Pancaroglu, R., \& Barton, J. (2014). Acquired prosopagnosia: structural basis and processing impairments. Front Biosci (Elite Ed), 6, 159-174. doi:E699 [pii]

De Haan, E. H., Young, A. W., \& Newcombe, F. (1991). Covert and overt recognition in prosopagnosia. Brain, 114 ( Pt 6), 2575-2591.

DeGutis, J., Cohan, S., Kahn, D., Aguirre, G., \& Nakayama, K. (2013). Facial Expression training improves emotion recognition and changes in neural tun- ing in a patient with acquired emotion recognition deficits and prosopagnosia. . Journal of Vision, 13, 993.

DeGutis, J., Cohan, S., Mercado, R. J., Wilmer, J., \& Nakayama, K. (2012). Holistic processing of the mouth but not the eyes in developmental prosopagnosia. Cognitive neuropsychology, 29(5-6), 419446.

DeGutis, J., Cohan, S., \& Nakayama, K. (2014). Holistic face training enhances face processing in developmental prosopagnosia. Brain, 137(Pt 6), 1781-1798. doi:10.1093/brain/awu062

DeGutis, J. M., Bentin, S., Robertson, L. C., \& D'Esposito, M. (2007). Functional plasticity in ventral temporal cortex following cognitive rehabilitation of a congenital prosopagnosic. J Cogn Neurosci, 19(11), 1790-1802. doi:10.1162/jocn.2007.19.11.1790

DeGutis, J. M., Chiu, C., Grosso, M. E., \& Cohan, S. (2014). Face processing improvements in prosopagnosia: successes and failures over the last 50 years. Front Hum Neurosci, 8, 561. doi:10.3389/fnhum.2014.00561

Duchaine, B., Germine, L., \& Nakayama, K. (2007). Family resemblance: Ten family members with prosopagnosia and within-class object agnosia. Cognitive neuropsychology, 24(4), 419-430.

Duchaine, B., \& Nakayama, K. (2005). Dissociations of face and object recognition in developmental prosopagnosia. J Cogn Neurosci, 17, 249-261.

Duchaine, B. C., \& Nakayama, K. (2006). The Cambridge face memory test: results for neurologically intact individuals and an investigation of its validityt using inverted face stimuli and prosopagnosic patients. Neuropsychologia, 44, 576-585.

Dwyer, D. M., \& Vladeanu, M. (2009). Perceptual learning in face processing: comparison facilitates face recognition. $Q J$ Exp Psychol (Hove), 62(10), 2055-2067. doi:10.1080/17470210802661736

Ellis, H. D., \& Young, A. W. (1988). Training in face-processing skills for a child with acquired prosopagnosia. Developmental Neuropsychology, 4(4), 283-294.

Fahle, M., \& Morgan, M. (1996). No transfer of perceptual learning between similar stimuli in the same retinal position. Current Biology, 6(3), 292-297.

Fendick, M., \& Westheimer, G. (1983). Effects of practice and the separation of test targets on foveal and peripheral stereoacuity. Vision Research, 23(2), 145-150.

Fenn, K. M., Nusbaum, H. C., \& Margoliash, D. (2003). Consolidation during sleep of perceptual learning of spoken language. Nature, 425(6958), 614-616.

Francis, R., Jane Riddoch, M. J., \& Humphreys, G. W. (2002). 'Who's that girl?' Prosopagnosia, personbased semantic disorder, and the reacquisition of face identification ability. Neuropsychol Rehabil, 12(1), 1-26.

Furmanski, C. S., \& Engel, S. A. (2000). Perceptual learning in object recognition: object specificity and size invariance. Vision Research, 40(5), 473-484.

Gais, S., Plihal, W., Wagner, U., \& Born, J. (2000). Early sleep triggers memory for early visual discrimination skills. Nature Neuroscience, 3(12), 1335-1339. 
Gilbert, C. D., \& Li, W. (2012). Adult visual cortical plasticity. Neuron, 75(2), 250-264. doi:S08966273(12)00592-2 [pii]

10.1016/j.neuron.2012.06.030

Gilbert, C. D., Sigman, M., \& Crist, R. E. (2001). The Neural Basis of Perceptual Learning. Neuron, 31(5), 681-697.

Hussain, Z., Sekuler, A. B., \& Bennett, P. J. (2009a). How much practice is needed to produce perceptual learning? Vision Res, 49(21), 2624-2634. doi:S0042-6989(09)00381-2 [pii]

10.1016/j.visres.2009.08.022

Hussain, Z., Sekuler, A. B., \& Bennett, P. J. (2009b). Perceptual learning modifies inversion effects for faces and textures. Vision Res, 49(18), 2273-2284. doi:S0042-6989(09)00306-X [pii]

10.1016/j.visres.2009.06.014

Jiang, X., Bradley, E., Rini, R. A., Zeffiro, T., Vanmeter, J., \& Riesenhuber, M. (2007). Categorization training results in shape- and category-selective human neural plasticity. Neuron, 53(6), 891-903. doi:S0896-6273(07)00114-6 [pii]

10.1016/j.neuron.2007.02.015

Kaernbach, C. (1991). Simple adaptive testing with the weighted up-down method. Attention, Perception, \& Psychophysics, 49(3), 227-229.

Karni, A., \& Sagi, D. (1991). Where practice makes perfect in texture discrimination: evidence for primary visual cortex plasticity. Proceedings of the National Academy of Sciences, 88(11), 4966-4970.

Karni, A., Tanne, D., Rubenstein, B. S., Askenasy, J. J., \& Sagi, D. (1994). Dependence on REM sleep of overnight improvement of a perceptual skill. Science, 265(5172), 679-682.

Kimchi, R., Behrmann, M., Avidan, G., \& Amishav, R. (2012). Perceptual separability of featural and configural information in congenital prosopagnosia. Cognitive neuropsychology, 29(5-6), 447-463.

Le Grand, R., Cooper, P. A., Mondloch, C. J., Lewis, T. L., Sagiv, N., de Gelder, B., \& Maurer, D. (2006). What aspects of face processing are impaired in developmental prosopagnosia? Brain and cognition, 61(2), 139-158.

Lee, Y., Duchaine, B., Wilson, H. R., \& Nakayama, K. (2010). Three cases of developmental prosopagnosia from one family: Detailed neuropsychological and psychophysical investigation of face processing. Cortex, 46(8), 949-964.

Mayer, E., \& Rossion, B. (2007). Prosopagnosia. In O. Godefroy \& J. Bogousslavsky (Eds.), The behavioural cognitive neurology of stroke (pp. 315-334). Cambridge: Cambridge University Press.

Moroz, D., Corrow, S. L., Corrow, J. C., Barton, A. R., Duchaine, B., \& Barton, J. J. (2016). Localization and patterns of Cerebral dyschromatopsia: A study of Subjects with Prospagnosia. Neuropsychologia. doi:10.1016/j.neuropsychologia.2016.06.012

Mundy, M. E., Honey, R. C., Downing, P. E., Wise, R. G., Graham, K. S., \& Dwyer, D. M. (2009). Material-independent and material-specific activation in functional MRI after perceptual learning. Neuroreport, 20(16), 1397-1401. doi:10.1097/WNR.0b013e32832f81f4

Mundy, M. E., Honey, R. C., \& Dwyer, D. M. (2007). Simultaneous presentation of similar stimuli produces perceptual learning in human picture processing. J Exp Psychol Anim Behav Process, 33(2), 124-138. doi:10.1037/0097-7403.33.2.124

Mundy, M. E., Honey, R. C., \& Dwyer, D. M. (2009). Superior discrimination between similar stimuli after simultaneous exposure. Q J Exp Psychol (Hove), 62(1), 18-25. doi:10.1080/17470210802240614

Palmeri, T. J., Wong, A. C., \& Gauthier, I. (2004). Computational approaches to the development of perceptual expertise. Trends Cogn Sci, 8(8), 378-386. doi:10.1016/j.tics.2004.06.001

Petrov, A. A., Dosher, B. A., \& Lu, Z. L. (2005). The dynamics of perceptual learning: an incremental reweighting model. Psychol Rev, 112(4), 715-743. doi:2005-13637-001 [pii] 


\subsection{7/0033-295X.112.4.715}

Pizzamiglio, M. R., De Luca, M., Di Vita, A., Palermo, L., Tanzilli, A., Dacquino, C., \& Piccardi, L. (2017). Congenital prosopagnosia in a child: Neuropsychological assessment, eye movement recordings and training. Neuropsychol Rehabil, 27(3), 369-408. doi:10.1080/09602011.2015.1084335

Polster, M., \& Rapcsak, S. (1996). Representations in learning new faces: Evidence from prosopagnosia. Journal of the International Neuropsychological Society, 2, 240--248.

Powell, J., Letson, S., Davidoff, J., Valentine, T., \& Greenwood, R. (2008). Enhancement of face recognition learning in patients with brain injury using three cognitive training procedures. Neuropsychol Rehabil, 18(2), 182-203. doi:10.1080/09602010701419485

Ramachandran, V., \& Braddick, O. (1973). Orientation-specific learning in stereopsis. Perception.

Sampaio-Baptista, C., Sanders, Z. B., \& Johansen-Berg, H. (2018). Structural Plasticity in Adulthood with Motor Learning and Stroke Rehabilitation. Annu Rev Neurosci, 41, 25-40. doi:10.1146/annurevneuro-080317-062015

Schmalzl, L., Palermo, R., Green, M., Brunsdon, R., \& Coltheart, M. (2008). Training of familiar face recognition and visual scan paths for faces in a child with congenital prosopagnosia. Cogn Neuropsychol, 25(5), 704-729. doi:10.1080/02643290802299350

Schmalzl, L., Palermo, R., Green, M., Brunsdon, R., \& Coltheart, M. (2008). Training of familiar face recognition and visual scan paths for faces in a child with congenital prosopagnosia. Cognitive neuropsychology, 25(5), 704--729.

Schoups, A. A., Vogels, R., \& Orban, G. A. (1995). Human perceptual learning in identifying the oblique orientation: retinotopy, orientation specificity and monocularity. The Journal of physiology, 483(3), 797-810.

Shah, P., Gaule, A., Sowden, S., Bird, G., \& Cook, R. (2015). The 20-item prosopagnosia index (PI20): a self-report instrument for identifying developmental prosopagnosia. Royal Society open science, 2(6), 140343.

Song, S., Garrido, L., Nagy, Z., Mohammadi, S., Steel, A., Driver, J., . . . Furl, N. (2015). Local but not long-range microstructural differences of the ventral temporal cortex in developmental prosopagnosia. Neuropsychologia, 78, 195-206. doi:10.1016/j.neuropsychologia.2015.10.010

Susilo, T., \& Duchaine, B. (2013). Advances in developmental prosopagnosia research. Curr Opin Neurobiol, 23(3), 423-429. doi:10.1016/j.conb.2012.12.011

Thomas, A. L., Lawler, K., Olson, I. R., \& Aguirre, G. K. (2008). The Philadelphia Face Perception Battery. Arch Clin Neuropsychol, 23(2), 175-187. doi:10.1016/j.acn.2007.10.003

Warrington, E. (1984). Warrington Recognition Memory Test. Los Angeles: Western Psychological Services.

Wetherill, G. B., \& Levitt, H. (1965). Sequential estimation of points on a psychometric function. British Journal of Mathematical and Statistical Psychology, 18(1), 1-10.

Wilson, B. A. (1987). Rehabilitation of Memory. New York, NY: Guilford Publications.

Wilson, C. E., Palermo, R., Schmalzl, L., \& Brock, J. (2010). Specificity of impaired facial identity recognition in children with suspected developmental prosopagnosia. Cogn Neuropsychol, 27(1), 30-45. doi:10.1080/02643294.2010.490207

Yardley, L., McDermott, L., Pisarski, S., Duchaine, B., \& Nakayama, K. (2008). Psychosocial consequences of developmental prosopagnosia: A problem of recognition. Journal of Psychosomatic Research, 65(5), 445-451. 
Younger, J., Gandhi, V., Hubbard, E., \& Mackey, S. (2012). Development of the Stanford Expectations of Treatment Scale (SETS): a tool for measuring patient outcome expectancy in clinical trials. Clin Trials, 9(6), 767-776. doi:10.1177/1740774512465064 